\title{
New Components for Dye-Sensitized Solar Cells
}

\author{
Stefano Caramori, ${ }^{1}$ Vito Cristino, ${ }^{1}$ Rita Boaretto, ${ }^{1}$ \\ Roberto Argazzi, ${ }^{2}$ Carlo Alberto Bignozzi, ${ }^{1}$ and Aldo Di Carlo ${ }^{3}$ \\ ${ }^{1}$ Dipartimento di Chimica, Università degli Studi di Ferrara, Via L. Borsari 46, 44100 Ferrara, Italy \\ ${ }^{2}$ Dipartimento di Chimica, Istituto per la Sintesi Organica e la Fotoreattività (ISOF-CNR) c/o, Università degli Studi di Ferrara, \\ Via L. Borsari 46, 44100 Ferrara, Italy \\ ${ }^{3}$ Dipartimento di Ingegneria Elettronica, Università di Roma “Tor Vergata”, Via del Politecnico 1, 00133 Roma, Italy \\ Correspondence should be addressed to Carlo Alberto Bignozzi, g4s@unife.it
}

Received 1 December 2009; Accepted 29 March 2010

Academic Editor: Gaetano Di Marco

Copyright () 2010 Stefano Caramori et al. This is an open access article distributed under the Creative Commons Attribution License, which permits unrestricted use, distribution, and reproduction in any medium, provided the original work is properly cited.

Dye-Sensitized Solar Cells (DSSCs) are among the most promising solar energy conversion devices of new generation, since coupling ease of fabrication and low cost offer the possibility of building integration in photovoltaic windows and facades. Although in their earliest configuration these systems are close to commercialization, fundamental studies are still required for developing new molecules and materials with more desirable properties as well as improving our understanding of the fundamental processes at the basis of the functioning of photoactive heterogeneous interfaces. In this contribution, some recent advances, made in the effort of improving DSSC devices by finding alternative materials and configurations, are reviewed.

\section{Introduction}

Dye-sensitized solar cells (DSSCs) are photoelectrochemical solar devices, currently subject of intense research in the framework of renewable energies being low-cost photovoltaic devices. DSSCs are based on the sensitization to visible light of mesoporous, nanocrystalline metal oxide films achieved by means of the adsorption of molecular dyes [1-3]. Photoinduced electron injection from the sensitizer dye (D) into the metal oxide conduction band initiates charge separation. Subsequently, the injected electrons are transported through the metal oxide film to a transparent electrode, while a redox-active electrolyte, such as $\mathrm{I}_{3}^{-} / \mathrm{I}^{-}$, is employed to reduce the dye cation and transport the resulting positive charge to a counter electrode (Figure 1).

DSSCs efficiencies up to $10.4 \%$ [4] have been reported for devices employing nanocrystalline $\mathrm{TiO}_{2}$ films. Several studies have addressed the use of alternative metal oxides including $\mathrm{SnO}_{2}[5,6], \mathrm{ZnO}[7,8]$, and $\mathrm{Nb}_{2} \mathrm{O}_{5}$ [9]. The performance of dye-sensitized solar cells can be understood in view of the kinetic competition among the various redox processes involved in the conversion of light into electricity. Ultrafast electron injection $\left(k_{2}\right)$ has been observed in the femtosecond-picosecond $\left(10^{-15}-10^{-12} \mathrm{~s}\right)$ time domain. Regeneration of the oxidized dye $\left(k_{4}\right)$ is typically characterized by rate constants of $10^{7}-10^{9} \mathrm{~s}^{-1}$. This is more than 100 times faster than recombination of injected electrons with the oxidized redox species $\left(k_{6}\right)$ and orders of magnitude faster than back transfer to the dye cation in the absence of a redox mediator $\left(k_{3}\right)$. As electron transport in the semiconductor electrode is generally one order of magnitude faster than recombination, the charge collection efficiency is near unit for optimized cells. Because of the prevailing role of electron transfer dynamics in DSSCs, the various processes have been widely studied in the last decade. While photo-electrochemical techniques proved to be most adequate for the study of electron transport, time-resolved optical spectroscopy remains the leading tool for the study of interfacial electron transfer. Dye regeneration and back transfer reactions have been intensely studied by nanosecond laser spectroscopy. On the other hand, due to its astonishing rate, the forward electron transfer reaction remained unresolved for several years: the advent of femtosecond laser spectroscopy opened the door to the domain of ultrafast chemical processes. 


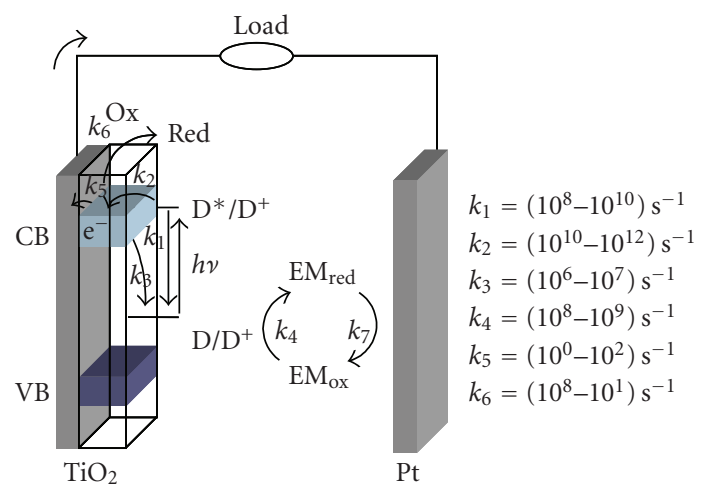

FIGURE 1: Electron transfer processes involved in a DSSC and their time scale.

The functioning of DSSCs is the interlacing of several subsystems which should work in tandem: the dye sensitizer, that is, the dye adsorbed on the semiconductor surface able to absorb the visible and near-IR photons and to pump electrons into the conducting band of semiconductor, the electron mediator for "hole", conduction and the counter electrode catalytic materials. We report here on the recent advances in the design of these DSSC components.

\section{Molecular Sensitizers}

One of the most important DSSC component, is the dye sensitizer, which represents the photodriven elctron pump of the device. It allows an independent electron injection into the semiconductor conduction band and conversion of visible and near infrared photons to electricity.

Several organic and inorganic compounds have been investigated for semiconductor sensitization, such as chlorophyll derivatives [10], porphyrins [11], phtalocyanines [12, 13], platinum complexes [14, 15], fluorescent dyes [16], carboxylated derivatives of anthracene [17], polymeric films [18], and coupled semiconductors with lower-energy bandgaps [19], among others.

The best solar to electric power conversion efficiency has been achieved with polypyridyl complexes of ruthenium(II) [20] and osmium(II) [21] bearing carboxylated ligands, which are often employed as $\mathrm{TiO}_{2}$ sensitizers in such cells. These species give rise to intense visible metal-to-ligand charge transfer (MLCT) bands with a favourable energetics for activationless charge injection. Among this family of compounds, excellent results have been achieved with thiocyanate derivatives. In particular, the performances of the $\mathrm{Ru}(\mathrm{II})$-NCS complexes (Figure 2). In photoelectrochemical solar cells were found to be outstanding $[20,22]$. The complexes show photoaction spectra dominating almost the entire visible region, short-circuit photocurrents exceeding $16 \mathrm{~mA} / \mathrm{cm}^{2}$ under simulated A.M. 1.5, sunlight and opencircuit photovoltages of the order of $0.7 \mathrm{~V}$ in the presence of $\mathrm{I}_{3}^{-} / \mathrm{I}^{-}$as redox electrolyte. Their high efficiency is related to hole delocalization across the NCS ligands $[23,24]$ which is responsible for an increased electronic coupling of the electron transfer reaction involving $\mathrm{TiO}_{2} / \mathrm{Ru}^{\mathrm{III}} \mathrm{NCS}$ and $\mathrm{I}^{-}$. This leads to an increase of the rate constant of the reductive process $\left(k_{4}\right.$, in Figure 1$)$ and, as a consequence, of the IPCE (Incident Photon to Carrier Efficiency).

The photoelectrochemical performances obtained with the mononuclear complex $\left[\mathrm{Ru}\left(\mathrm{dcbH}_{2}\right)_{2}(\mathrm{NCS})_{2}\right]$ have been surpassed by an analogous species based on the terpyridine ligand [4]. Indeed, $\mathrm{TiO}_{2}$ electrodes covered with the complex $\mathrm{Ru}(\mathrm{L})(\mathrm{NCS})_{3}\left(\mathrm{~L}=4,4^{\prime}, 4^{\prime \prime}\right.$-tricarboxy- $2,2^{\prime}: 6^{\prime}, 2^{\prime \prime}$ terpyridine) in its monoprotonated form displayed very efficient panchromatic sensitization covering the whole visible spectrum and extending the spectral response to the near IR region, up to $920 \mathrm{~nm}$, with maximum IPCE values comparable to that obtained with the dithiocyanate complex. The panchromatic efficiency has been further extended in a series of cationic dyes, corresponding to the general formulae $\left[\mathrm{M}\left(\mathrm{H}_{3} \text { tcterpy }\right) \mathrm{LY}\right]^{+}$[25]: $\mathrm{M}=\mathrm{Os}(\mathrm{II})$ or $\mathrm{Ru}(\mathrm{II})$; $\left(\mathrm{H}_{3}\right.$ tcterpy) is the tridentate ligand, 4,4', $4^{\prime \prime}$-tricarboxy$2,2^{\prime}: 6^{\prime}, 2^{\prime \prime}$-terpyridine, and $\mathrm{L}$ is a bidentate ligand of the type (bpy, 2,2'-bipyridine) or (pyq, 2-2'-pyridylquinoline) (Figure 3), which can be substituted both in the 4 and $4^{\prime}$ positions by $\mathrm{X}=\mathrm{H}, \mathrm{CH}_{3}, \mathrm{COOH}$, or $\mathrm{C}\left(\mathrm{CH}_{3}\right)_{3}$, and $\mathrm{Y}=$ $\mathrm{Cl}^{-}, \mathrm{I}^{-}$, or $\mathrm{NCS}^{-}$. These dyes show reversible metal oxidations and, in the Os case, unprecedented photoconversion efficiency in the near infrared (NIR), approaching in the best case the value of $50 \%$ at $900 \mathrm{~nm}$.

Many attempts to replace the thiocyanate donor ligands have been made, because the monodentate $\mathrm{NCS}^{-}$is believed to be the weakest part of the complexes from the chemical stability point of view. Recently a novel thiocyanate-free cyclometalated ruthenium complex containing the 2-(2,4Difluorophenyl)pyridine has been observed to produce a remarkable incident monochromatic photon-to-current conversion efficiency of 83\% [26]. The solar cell employing a liquid-based electrolyte exhibits a short circuit photocurrent density of $17 \mathrm{~mA} / \mathrm{cm}^{2}$, an open circuit voltage of $800 \mathrm{mV}$, and a fill factor of 0.74 , corresponding to an overall conversion efficiency of $10.1 \%$ at standard AM 1.5 sunlight.

Besides metal organic dyes, relevant efforts are currently being directed towards the synthesis of novel types of ruthenium-free organic dye sensitizers which display intense visible bands and favourable ground and excited state energetics. Usually the organic dye efficiency is lower than that displayed by MLCT complexes, but considerable success has been recently met with a careful synthetic design of chlorophylls [27] push-pull porphyrins [26, 28], phtalocyanins [29], and some squaraine dyes [30], particularly suited to harvest the NIR portion of the solar spectrum.

Fruit and vegetable extracts have also been used as natural sensitizers in photoelectrochemical solar cells [31, 32]. The interest in natural dyes arises from the possibility of achieving an efficient sensitization without expensive and time consuming synthetic and purification procedures. Among raw natural dyes, cyanines and betalains have achieved maximum monochromatic photon to electron conversions exceeding $60 \%$ and short circuit photocurrents approaching $10 \mathrm{~mA} / \mathrm{cm}^{2}$, under $0.1 \mathrm{~W} / \mathrm{cm}^{2}$ simulated solar irradiation. Red turnip, wild prickly pear, and eggplant were identified, up to now, as, respectively, the best natural sources 


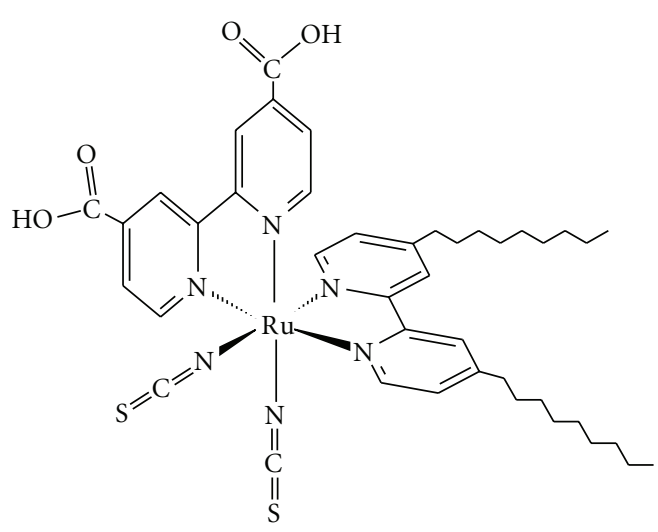

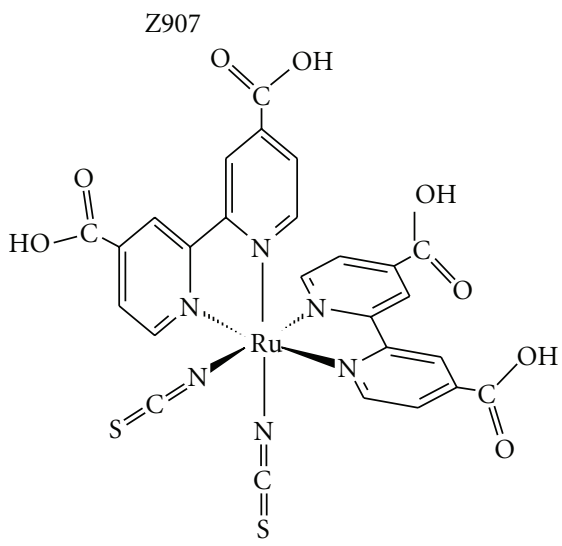

N3

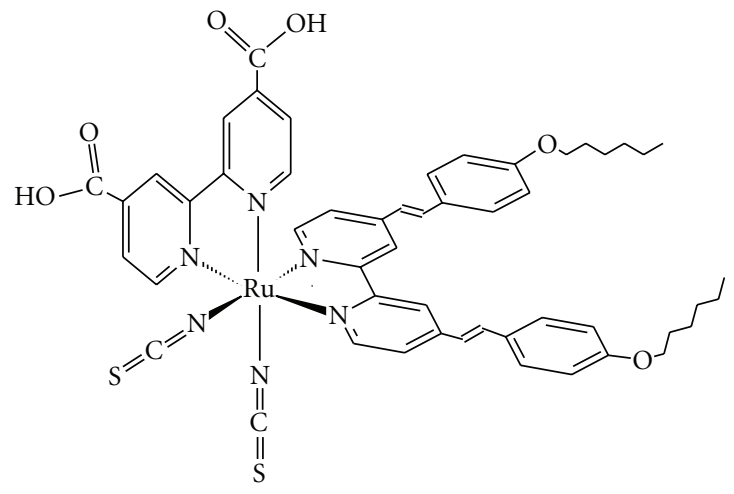

K19

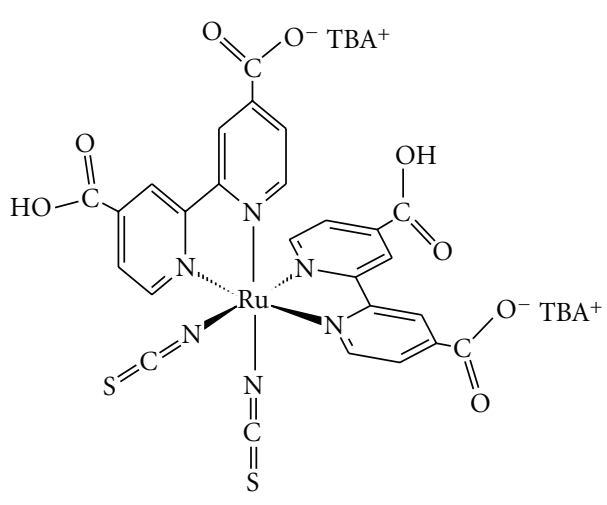

N719

FIgURE 2: Structure of some of the most successful polypyridine Ru(II) dye based on the NCS ancillary ligand.

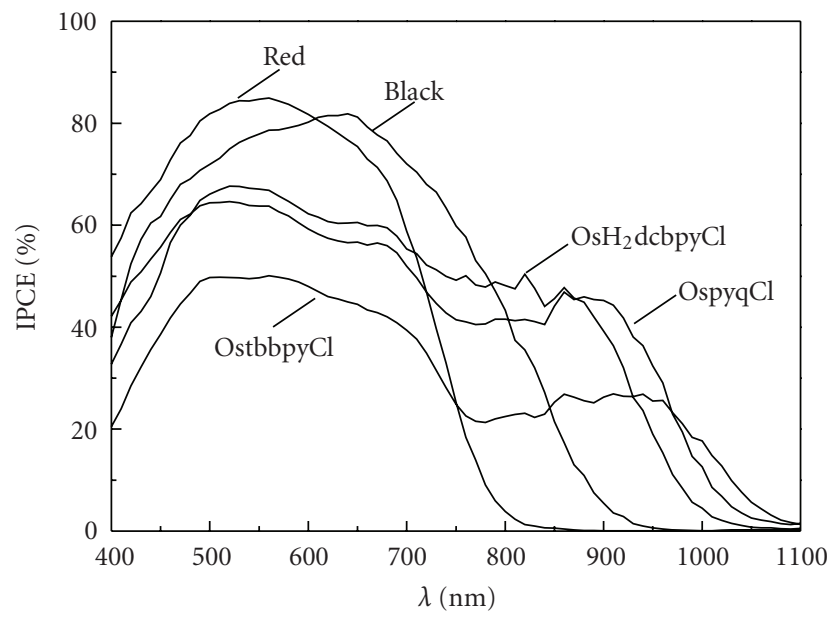

Figure 3: Photoaction spectra of Os dyes measured in sandwich type solar cells (nanocrystalline $\mathrm{TiO}_{2}$ films, electrolyte made of $2 \mathrm{M}$ $\mathrm{LiI}+0.1 \mathrm{M} \mathrm{I}_{2}$ in $\gamma$-butyrolactone $) . \mathrm{OsH}_{2} \mathrm{dcpyCl}=\left[\mathrm{Os}\left(\mathrm{H}_{3} \text { tcterpy }\right)\left(\mathrm{H}_{2} \mathrm{dcbpy}\right)(\mathrm{Cl})\right]^{+} ;$OstbbpyCl $=\left[\mathrm{Os}\left(\mathrm{H}_{3} \mathrm{tcterpy}\right)(\mathrm{tbbpy})(\mathrm{Cl})\right]^{+} ; \mathrm{OspyqCl}=$ $\left[\mathrm{Os}\left(\mathrm{H}_{3} \text { tcterpy }\right)(\text { pyq })(\mathrm{Cl})\right]^{+}$. Red and black dye are $\mathrm{N} 3$ and $\mathrm{Ru}\left(\mathrm{H}_{3}\right.$ Tcterpy $)(\mathrm{NCS})_{3}^{-}$, respectively.

of betalain and antocyanines pigments for $\mathrm{TiO}_{2}$ sensitization (Figure 4).

In general, the natural dyes tested so far suffer from low $\operatorname{Voc}(440-480 \mathrm{mV})$ which is at best $100 \mathrm{mV}$ lower than an equivalent N 719 sensitized cell. This can be due to possible efficient electron/dye cation recombination pathways and to the acidic dye adsorption environment. In fact, it is necessary an acidic environment to obtain a satisfactory dye coverage of the semiconductor surface and it is well known that $\mathrm{H}^{+}$are potential determining ions for $\mathrm{TiO}_{2}$ causing a positive shift of the Fermi level of the $\mathrm{TiO}_{2}$ and limiting the maximum photovoltage that can be delivered by the cells. Electron/dye 


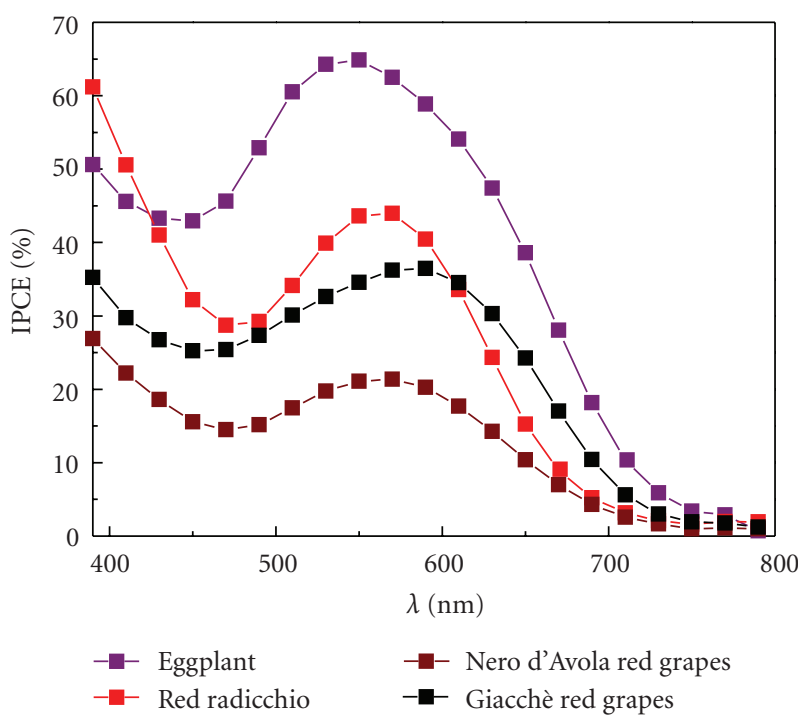

(a)

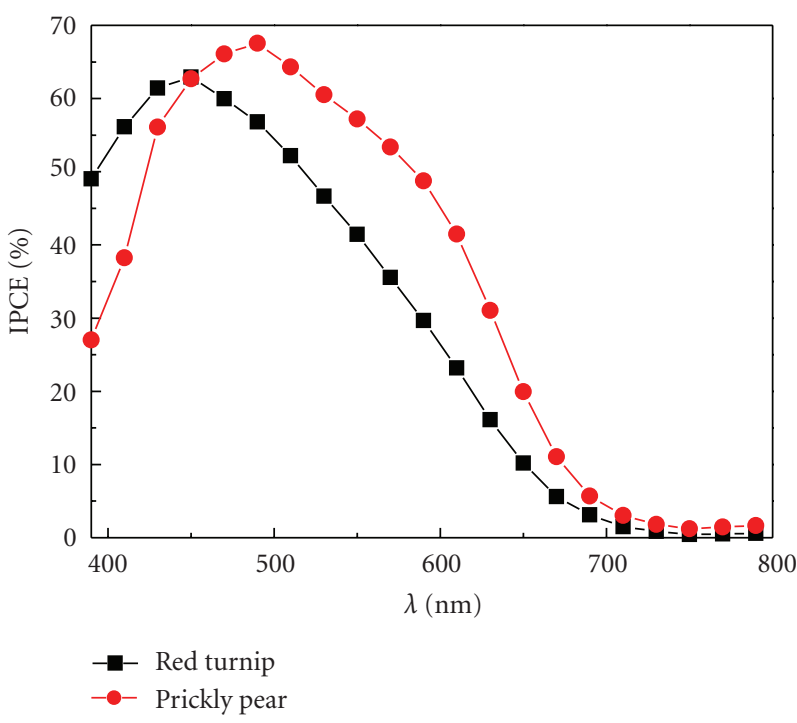

(b)

FIGURE 4: Photoaction spectra on transparent $\mathrm{TiO}_{2}$ of (a) anthocyanine raw extracts from eggplant (purple), red radicchio (red), Giacchè red grapes (black), and Nero d'Avola red grapes (brown); (b) betalains from red turnip (black) and wild prickly pear (red). LiI/ $\mathrm{I}_{2}$ 0.5 M/0.05 M in $\mathrm{ACN}$ was used as a redox electrolyte.

cation recombination can also be critical compared to ruthenium sensitizers, in which the hole is confined into a metal centred $\mathrm{d}$ orbital relatively decoupled from the semiconductor surface. Electron recapture by smaller flat organic molecules is expected to be faster, since the hole is probably located in closer proximity to the nanoparticle surface. Indeed the spectroscopic investigation of series of cyanine dyes showed electron/hole recombination lifetimes lower than $200 \mathrm{~ns}$.

\section{Electron Mediators Based on Coordination Compounds}

So far the $\mathrm{I}_{3}^{-} / \mathrm{I}^{-}$couple has been the most efficient and commonly used redox mediator in DSSCs, due to the fast regeneration of the oxidized dye provided by $\mathrm{I}^{-}$on a nanosecond time scale $[33,34]$ (Figure 5). The reduction of $\mathrm{I}_{3}^{-}$is a complex multistep reaction involving the breaking of chemical bonds: some authors [35, 36] have studied it in great detail and suggested a first dissociation of $\mathrm{I}_{3}^{-}$in $\mathrm{I}^{-}$ and $\mathrm{I}_{2}$, a subsequent reduction of $\mathrm{I}_{2}$ to $\mathrm{I}_{2}^{-}$followed by the rate limiting dismutation of two $\mathrm{I}_{2}^{-}$to give $\mathrm{I}^{-}$and $\mathrm{I}_{3}^{-}$. The same authors suggested that the reduction of $\mathrm{I}_{2}$ occurs only with adsorbed $\mathrm{I}_{2}$ molecules and the overall process is further slowed down by its relatively low concentration compared to $\mathrm{I}_{3}^{-}$in solution; moreover it is efficiently catalyzed by the presence of $\mathrm{Pt}$ at the counter electrode.

The electronic recapture involving $\mathrm{I}_{3}^{-}$is kinetically so slow on both $\mathrm{TiO}_{2}$ and FTO surfaces that, under short circuit conditions, most of electrons survive the transit through the mesoporous film and the FTO surface and appear in the external circuit. In summary, the forward electron donation by $\mathrm{I}^{-}$is a facile monoelectronic process which

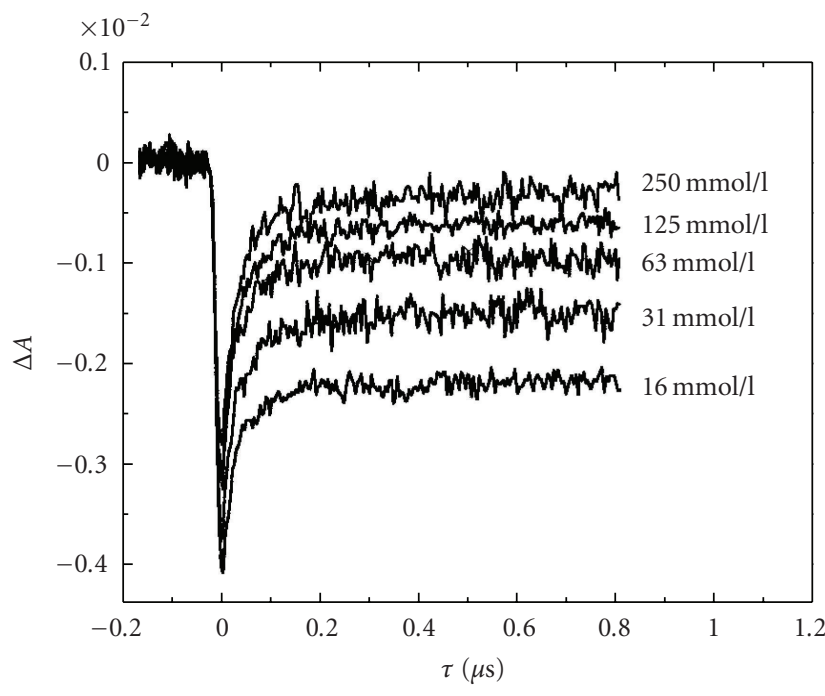

FIGURE 5: N3 recovery in presence of increasing concentration of $\mathrm{NaI}$ in acetonitrile.

ensures an efficient dye recovery $\left(k_{4}\right.$ in Figure 1), while the reduction of $\mathrm{I}_{3}^{-}$appears to be largely inefficient allowing for a minimization of the interfacial back recombination $\left(k_{6}\right.$ in Figure 1).

In other respects the $\mathrm{I}_{3}^{-} / \mathrm{I}^{-}$redox couple is less than ideal for a number of reasons: $I_{2}$ in equilibrium with $I_{3}^{-}$is volatile, complicating long-term cell sealing; $\mathrm{I}_{3}^{-}$is darkly colored and limits the light harvesting efficiency of the dye; DSSC cathodes require platinum coatings to effectively catalyze the $\mathrm{I}_{3}^{-}$reduction. Most importantly, $\mathrm{I}_{3}^{-} / \mathrm{I}^{-}$is corrosive towards many highly conductive metals, posing a serious problem for the scaling up of the solar cells to large areas which 


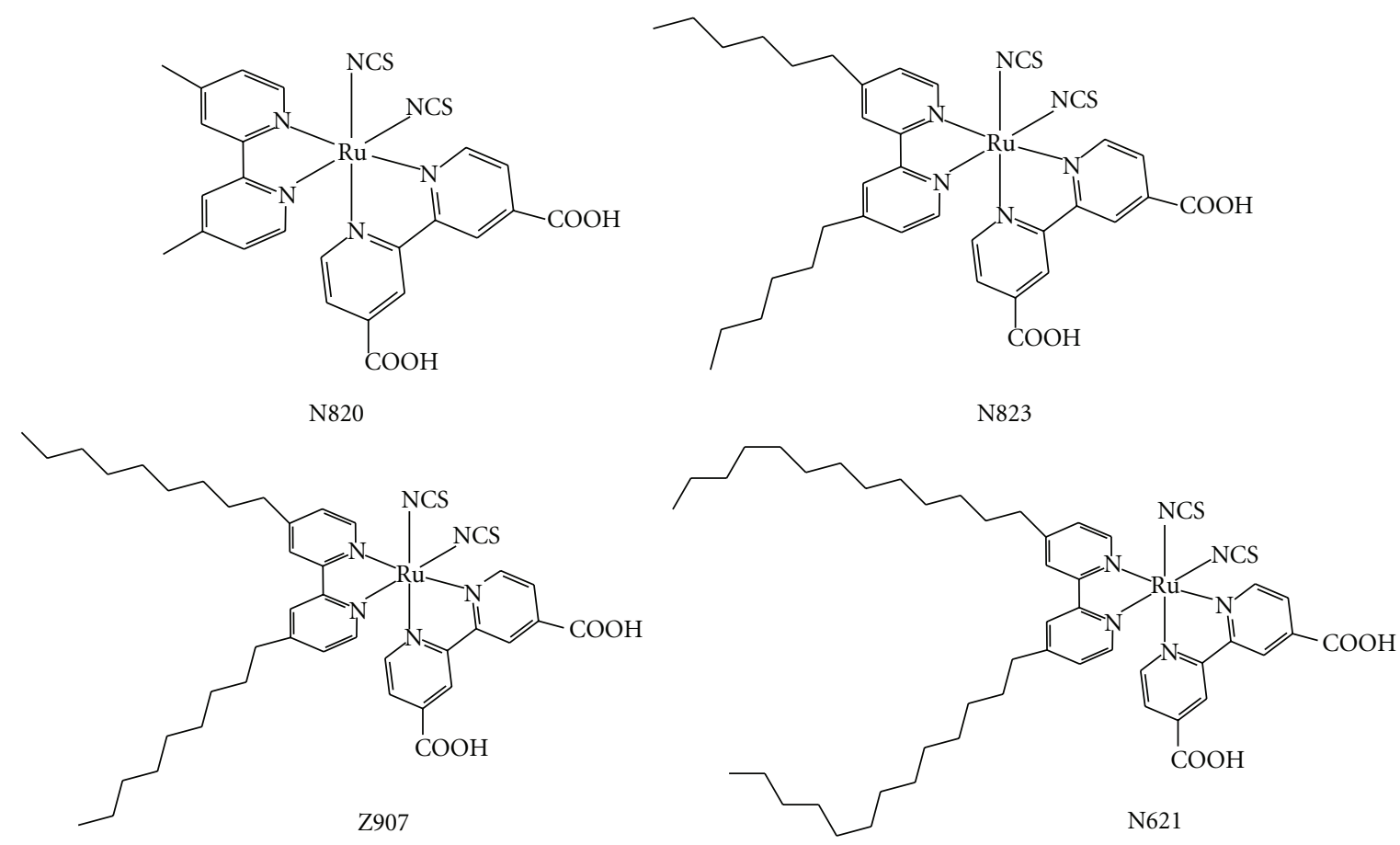

FIgURE 6: Heteroleptic dyes used in conjunction to cobalt electron transfer mediators.

requires the use of metallic grids deposited on FTO in order to minimize ohmic losses due to the high sheet resistance of the transparent conductive substrate. Besides these practical problems the search for new electron transfer mediators potentially capable of replacing the $\mathrm{I}_{3}^{-} / \mathrm{I}^{-}$couple is challenging for a number of reasons related to the strict requirements that must be fulfilled by an efficient electron mediator: it has to intercept efficiently the oxidized form of the dye, recombine slowly with photoinjected electrons on both $\mathrm{TiO}_{2}$ and FTO substrates, and allow for an efficient mass transport in solution and into the $\mathrm{TiO}_{2}$ mesopores. To our knowledge, there is no certain a priori indication that such requirements would be satisfied by a given chemical species on a specific substrate; however, in principle, every system characterized by a high reorganization energy associated to the electron transfer should exhibit a slow kinetics. In the following we report on the main attempts made to develop and improve new redox systems for DSSCs based on coordination compounds and on conductive polymers.

The electrochemical properties of coordination compounds can be tuned through a rational choice of the metal and an appropriate design of the coordination sphere. These features might guarantee the necessary flexibility to project an electron transfer mediator capable of meeting the kinetic requirements outlined above. In principle, to minimize recombination, kinetically slow couples have to be privileged. The relatively high concentration of electrolyte employed in photoelectrochemical cells $(0.1-0.5 \mathrm{M}$ in redox active species) demands for inexpensive and available metals, like the elements of the first transition row, and easily synthesizable ligands. To date, the most successful attempts have been based on octahedral cobalt(II) and tetrahedral copper(I) complexes. The $\mathrm{Co}(\mathrm{II}) /(\mathrm{III})$ couple is usually characterized by an high inner sphere reorganization energy associated to the electron transfer, essentially due to the involvement of a metal centred $\mathrm{e}_{g}$ redox orbital with antibonding characteristics.

One of the first reports by Graetzel and coworkers was focused on the use of a one-electron $\mathrm{Co}$ (II) redox mediator based on the Co(II)-bis-[2,6-bis(1'-butylbenzimidazol-2' yl)pyridine] [37] (dbbip) complex. The Co(III)(dbbip) ${ }_{2}^{3+} /$ $\mathrm{Co}(\mathrm{II})(\mathrm{dbbip})_{2}^{2+}$ potential was of $0.36 \mathrm{~V}$ versus SCE, a value comparable with that of the $\mathrm{I}_{3}^{-} / \mathrm{I}^{-}$couple. Used in conjunction with a compact blocking $\mathrm{TiO}_{2}$ underlayer, whose function is devoted to the minimization of the dark current (recombination with $\mathrm{Co}$ (III)), $\mathrm{Co}(\text { dbbip) })_{2}$ appeared to rival the $\mathrm{I}_{3}^{-} / \mathrm{I}^{-}$performances in terms of IPCE and global cell efficiency. Encouraging was also the weak coloration of the complex which exhibited a moderate absorption in the visible region with an extinction coefficient of the order of $10^{2} \mathrm{~mol}^{-1} \mathrm{~cm}^{-1}$ at $450 \mathrm{~nm}$. The best results with this type of cobalt mediators were obtained using heteroleptic complexes like Z907 and N 621 bearing long alkyl chains (Figure 6).

The use of heteroleptic dyes [38, 39] brings two main advantages: reduction of the ion pairing effect due to a smaller negative $\zeta$ potential and suppression of the electron tunnelling to $\mathrm{Co}$ (III) acceptors caused by the steric hindrance of the long alkyl chains, which limit the access of the cobalt complex to the exposed $\mathrm{TiO}_{2}$ surface, thus reducing the probability of electron recapture as evident from the cell dark current measurements. For similar reasons the cografting of long alkyl chain carboxylic acids like hexadecylmalonic acid allowed for an enhancement of the photovoltaic response of cobalt-mediated cells [39]. One of the limitations of Co(II) benzimidazol complexes is related to the multistep synthetic procedure for the ligand preparation. 


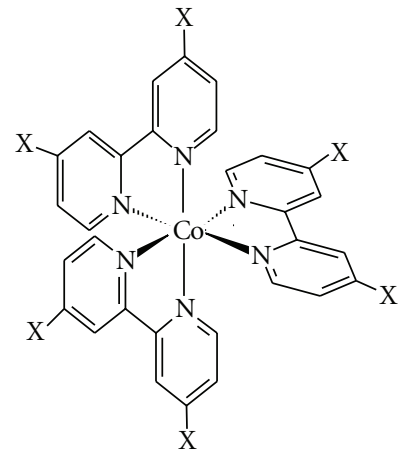

(a)

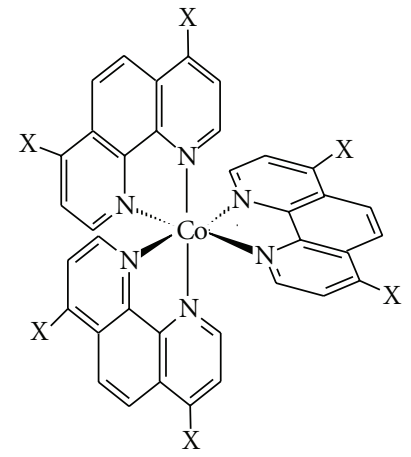

(b)

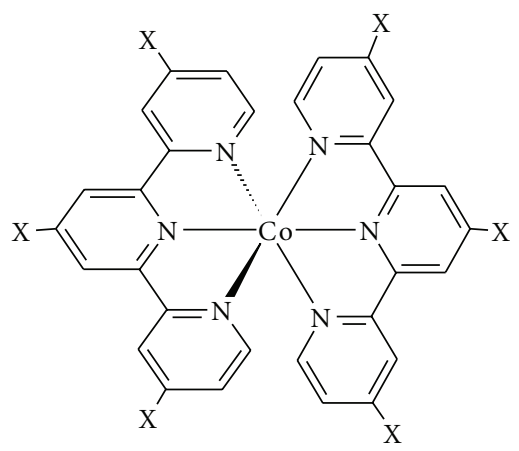

(c)

Figure 7: Structure of polypyridilic Co(II) complexes: (a) X = Tert-butyl (DTB), Methyl (DMB), H (bpy). (b) X = H (phen). (c) X = Tert-butyl (tTbterpy), Ethyl (tEterpy).

Almost contemporarily to the efforts made at the Swiss Federal Institute of Technology of Lausanne, it was found that particular cobalt polypyridine complexes, formed from structurally simple ligands, did function as efficient electrontransfer mediators in DSSCs [40].

The main focus of the investigation was thus to identify which structural and thermodynamic motifs generate the best mediators, allowing for the assembly of cells with the closest match to the performance of the $\mathrm{I}_{3}^{-} / \mathrm{I}^{-}$mediator.

The cobalt complexes reported in Figure 7 can be easily produced by mixing 1 equivalent of $\left[\mathrm{Co}\left(\mathrm{H}_{2} \mathrm{O}\right)_{6}\right]^{2+}$ with 3 equivalents of a bidentate ligand or 2 equivalents of a tridentate ligand under magnetic stirring in refluxing methanol for 2 hours. Addition of ethyl ether results in the precipitation and isolation of the product which is then usually used without any further purification.

All of the complexes under consideration exhibit similar UV-Vis absorption spectra characterized by a weak absorption band centred at ca. $440-450 \mathrm{~nm}$ and a ligand-based $\pi-\pi^{*}$ transition above $350-380 \mathrm{~nm}$.

The most intense visible absorption is for $\operatorname{Co}(\mathrm{tTbterpy})_{3}^{2+}$ with $\varepsilon_{450}=1.4 \leftarrow 10^{3} \mathrm{M}^{-1} \mathrm{~cm}^{-1}$ while the other complexes exhibit $\varepsilon_{440-450}$ values that are approximately an order of magnitude smaller. For the sake of comparison, the $\varepsilon_{440-450}$ value for $\mathrm{I}_{3}^{-}$is ca. $2 \leftarrow 10^{3} \mathrm{M}^{-1} \mathrm{~cm}^{-1}$; therefore, except $\mathrm{Co}$ (tTbterpy) ${ }_{3}^{2+}$ that has a comparable absorbance, considerably less visible light is absorbed by all of the remaining cobalt complexes at similar concentrations.

Electrochemical characterization of these complexes revealed an unexpected electrode material dependence to the electron-transfer kinetics. In the case of $4-4^{\prime}$ substituted polypyridine $\mathrm{Co}$ (II) complexes, gold electrodes exhibit the most reversible and ideally shaped CVs. Glassy carbon and platinum electrodes also produce quasireversible voltammograms, although less reversible than gold. In general, the shapes of the quasireversible waves indicate that, in cases where the heterogeneous electron transfer is slow, the transfer coefficient, $\alpha$, is considerably greater than 0.5 . In other words, for equivalent overpotentials the heterogeneous reduction of the $\mathrm{Co}$ (III) complex is considerably faster than the corresponding oxidation of the $\mathrm{Co}$ (II) species. The

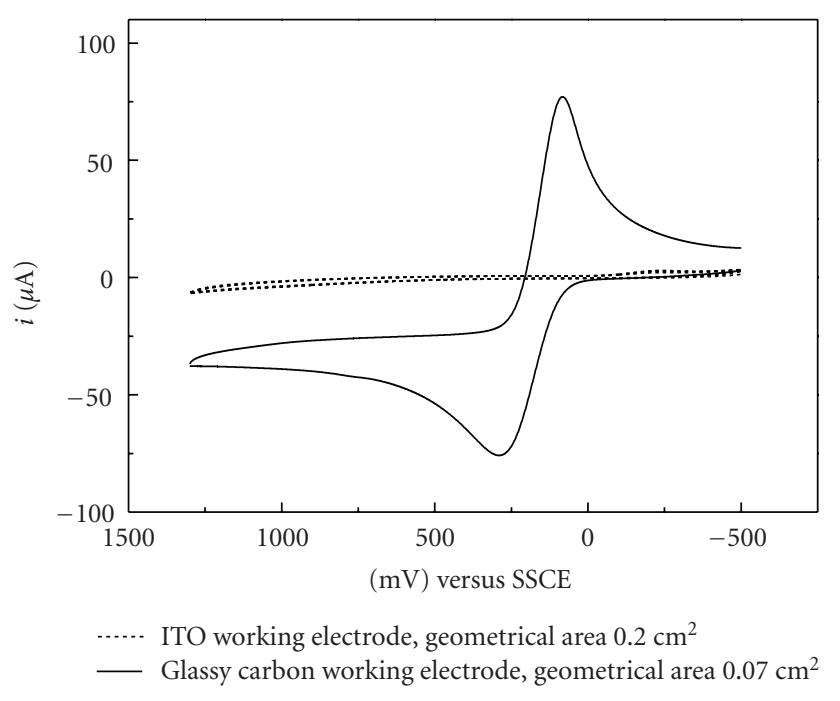

FIGURE 8: Cyclic voltammetry of approximately $1 \times 10^{-3} \mathrm{M}$ $\mathrm{Co}(\mathrm{DTB})_{3}^{2+}$ recorded in $\mathrm{ACN} \mathrm{TBAPF}_{6} 0.1 \mathrm{M}$ on GC (solid line) and on ITO (dotted line).

voltammetric results also suggest that while platinum is the cathode of choice for the $\mathrm{I}_{3}^{-} / \mathrm{I}^{-}$redox mediator, it should not be the optimal choice for cobalt complex-based mediators. Likewise, while carbon has long been considered a poor cathode for $\mathrm{I}_{3}^{-} / \mathrm{I}^{-}$, it should be acceptable for any of the cobalt systems considered here. It should be considered that only very recently significant results concerning alternative highperformance counter electrodes for the $\mathrm{I}_{3}^{-} / \mathrm{I}^{-}$couple, based on particular carbonaceous materials (nanotubes, graphene, carbon black), have been reported [41-44]. It must be noted that, among the series of Figure 7, one of the most promising cobalt complexes $\left(\mathrm{Co}(\mathrm{DTB})_{3}^{2+}\right)$ is nearly electrochemically inactive on FTO and ITO electrodes (Figure 8), meaning that the unwanted $\mathrm{Co}$ (III) to $\mathrm{Co}$ (II) reduction at the photoanode requires high overpotentials to be effective.

The dramatic dependence of the $\mathrm{Co}(\mathrm{DTB})_{3}^{2+/ 3+}$ heterogeneous electron transfer rate on the chemical nature of the electrode surface is most probably consequence of specific 


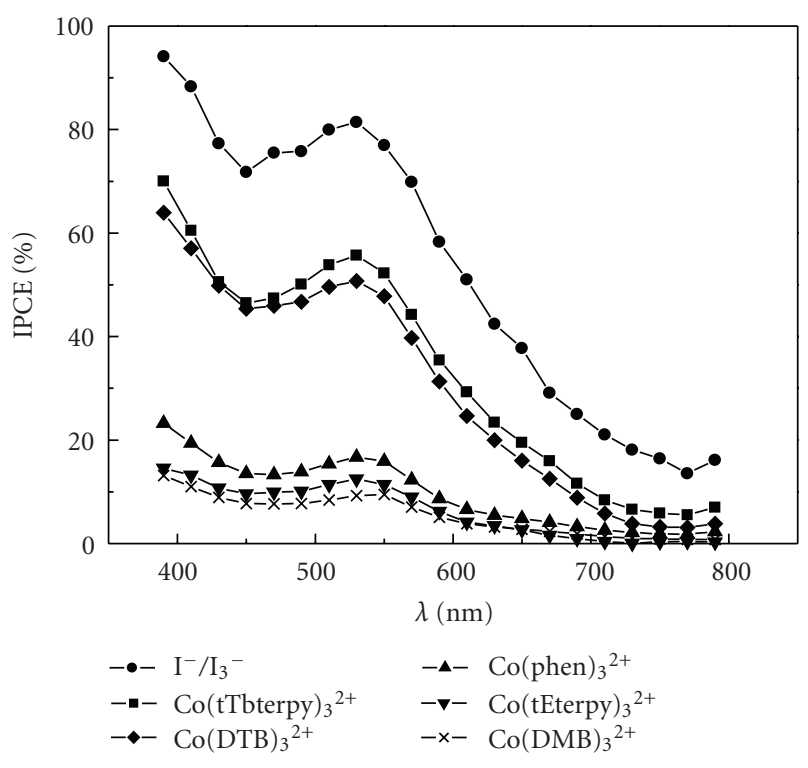

FIGURE 9: Photoaction spectra of $\mathrm{N} 3$ bound to nanocrystalline $\mathrm{TiO}_{2}$ films in the presence of different electron mediators in MPN solutions: $0.25 \mathrm{M} \mathrm{LiI} / 25 \mathrm{mM} \mathrm{I}_{2}$ (circles), $\left.0.25 \mathrm{M} \mathrm{Co(tTBterpy)}\right)_{2}^{2+} / 25 \mathrm{mM}$ $\mathrm{NOBF}_{4}$ (squares), $0.25 \mathrm{M} \mathrm{Co}(\mathrm{DTB})_{3}^{2+} / 25 \mathrm{mM} \mathrm{NOBF}_{4}$ (diamonds), $0.25 \mathrm{M} \mathrm{Co}$ (phen) $)_{3}^{2+} / 25 \mathrm{mM} \mathrm{NOBF}_{4}$ (triangles), $0.25 \mathrm{M} \mathrm{Co(tEt-}$ erpy $)_{2}^{2+} / 25 \mathrm{mM} \mathrm{NOBF}_{4}$ (upside down triangles), and saturated $(<0.15 \mathrm{M}) \mathrm{Co}(\mathrm{DMB})_{3}^{2+} / 25 \mathrm{mM} \mathrm{NOBF}_{4}$ (crosses). $0.25 \mathrm{M} \mathrm{LiClO}_{4}$ was added to all solutions containing a cobalt mediator.

interactions between the surface and the electroactive species which modify the electronic coupling and/or the activation barrier for the heterogeneous electron-transfer reaction. The electrochemical behaviour on metal oxide surfaces is in this case similar to that of the $\mathrm{I}_{3}^{-} / \mathrm{I}^{-}$couple for which the electron transfer from the FTO substrate to $\mathrm{I}_{3}^{-}$is a very slow multistep process [45].

The performances of the photoelectrochemical cells are strongly dependent on the composition of the electrolyte solution (Figure 9).

A maximum conversion efficiency of ca. $80 \%$, in correspondence to the metal-to-ligand charge transfer absorption maximum of $\mathrm{N} 3$, was obtained in the presence of $0.25 \mathrm{M}$ $\mathrm{LiI} / 0.025 \mathrm{M} \mathrm{I}_{2}$, whereas, with the cobalt based mediators, the best performances (IPCE ca. 50\%-55\%) were observed when solutions of $\mathrm{Co}(\mathrm{DTB})_{3}^{2+/ 3+}$ and $\mathrm{Co}(\mathrm{tTBterpy})_{2}^{2+/ 3+}$ were used. $\mathrm{Co}(\text { phen })_{3}^{2+/ 3+} \mathrm{Co}(\text { tEterpy })_{2}^{2+/ 3+}$ and $\mathrm{Co}(\mathrm{DMB})_{3}^{2+/ 3+}$ mediators exhibited much lower conversions, with maximum IPCE values in the range of $10 \%-20 \%$.

Generally, cobalt complexes of unsubstituted and methylsubstituted bipyridine or terpyridine ligands are poor electron transfer mediators in the type of DSSCs considered herein. In contrast, if the ligand contains a tertiary butyl substituent in the para position, the resulting cobalt-based cells yield quite good IPCE. The observed substituent effect cannot be related to an electronic perturbation of the $\mathrm{Co}$ (II) redox orbitals and to a consequent modification of the electrochemical properties of the coordination compound, since the electron-donating effect of all simple alkyl substituents (e.g., methyl, ethyl, tert-butyl, etc.) is essentially the same [46] and all of the complexes of a given ligand-type (i.e., bipyridine, phenanthroline, or terpyridine) were expected and found to have very similar $E_{1 / 2}(100-200 \mathrm{mV}$ versus $\mathrm{SCE}$ ) values for the relevant $\mathrm{Co}(\mathrm{II} / \mathrm{III})$ couple.

Nanosecond transient absorption experiments allowed for the rationalization of the lower efficiency of the Co-based couples with respect to $\mathrm{I}_{3}^{-} / \mathrm{I}^{-}$and for the clarification of their structure-dependent performance. Figure 10(a) shows the decay of the photogenerated N3 dye cation, observed at $480 \mathrm{~nm}$ in the presence of $\mathrm{Co}(\mathrm{DTB})_{3}^{2+} 0.1 \mathrm{M}$ and TBAI $0.1 \mathrm{M}$ : in both cases a $\tau_{2 / 3}$ of about $0.35 \mu$ s indicates that dye regeneration by $\mathrm{I}^{-}$and by $\mathrm{Co}(\mathrm{II})$ occurs at a very similar rate.

Upon $\mathrm{Li}^{+}$addition (Figure 10(b)) an increased reduction rate by iodide is observed $\left(\tau_{2 / 3}=0.12 \mu \mathrm{s}\right)$, whereas regeneration of the oxidized dye by $\mathrm{Co}(\mathrm{II})$ is substantially unchanged. Indeed, $\mathrm{TiO}_{2}$ surface adsorption/intercalation by $\mathrm{Li}^{+}$creates a positive polarization which attracts a surface excess of iodide in close proximity of the dye sites, allowing for a faster interception of the oxidized sensitizer. The same effect is obviously absent in the case of positively charged $\mathrm{Co}$ (II) complexes which do not experience any attraction with a positively polarized photoelectrode.

Recombination of injected electrons with the oxidized mediator could be particularly serious in the case of $\mathrm{Co}(\mathrm{II}) /(\mathrm{III})$ electron transfer mediators in which the outer sphere monoelectronic $\mathrm{Co}(\mathrm{III})$ reduction at the photoanode could be considerably more efficient than the multistep $\mathrm{I}_{3}^{-}$ reduction.

The process can be probed by means of transient spectroscopy following the time evolution of dye-cation bleaching. Reduction of the oxidized mediator by photoinjected electrons results in a slowing down of dye absorption recovery.

From Figure 11(a) it is evident that $\mathrm{I}_{3}^{-}$gives rise to the smallest increase in $\tau_{2 / 3}$ of the oxidized sensitizer, meaning that the $\mathrm{CB}$ electron interception has the lowest efficiency within the series of mediators explored so far. On the other hand $\mathrm{Co}(\mathrm{III})$ complexes produce a consistent increase in the recovery time of $\mathrm{N}^{+}$(Figures 10(a) and 10(b)), showing that the back electron transfer from $\mathrm{TiO}_{2}$ (or from the exposed $\mathrm{SnO}_{2}$ back contact) is more efficient than in the case of $\mathrm{I}_{3}^{-}$. It is also evident that $\mathrm{Co}(\mathrm{bpy})_{3}^{3+}$ is by far more effective than $\mathrm{Co}(\mathrm{DTB})_{3}^{3+}$ in recombining with photoinjected electrons. This behaviour is a convincing evidence that $\mathrm{Co}(\mathrm{II}) /(\mathrm{III})$ mediators need bulky substituents to minimize the undesired recombination with $\mathrm{CB}$ electrons. On the other hand, ligandmediated recombination can be safely excluded, since their reduction potential is generally too negative (about $-1 \mathrm{~V}$ versus SCE) to be accessible for $\mathrm{TiO}_{2}$ conduction band electrons.

In the effort of improving the performance of such mediators the possibility of using kinetically fast couples in conjunction with the best $\mathrm{Co}$ (II) mediators has been explored [47].

Kinetically fast couples efficiently reduce the oxidized dye, but due to the fast recombination with injected electrons, are totally unsuccessful as mediators in DSSCs. However, when mixed with an excess of cobalt mediator, if 


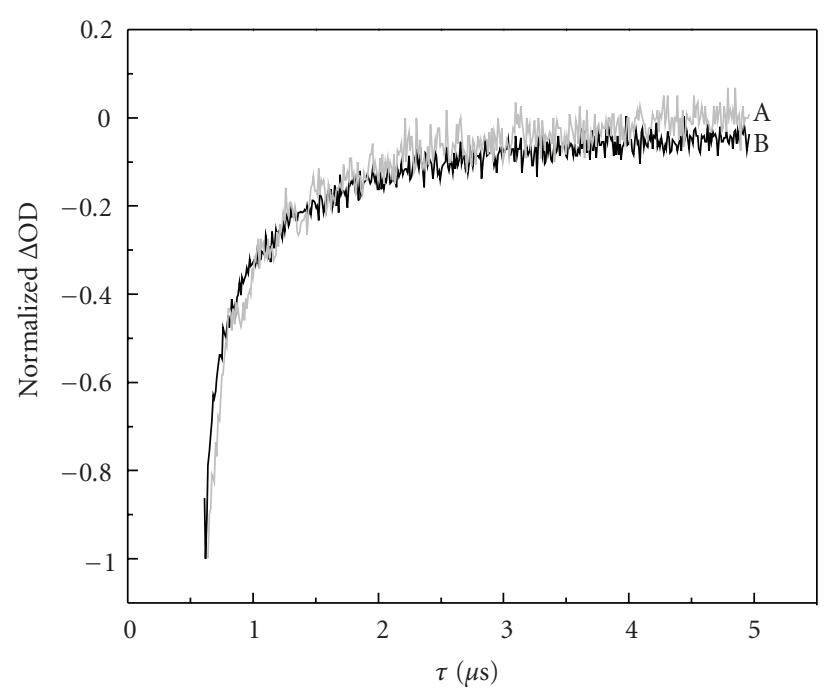

A: TBAI

B: $\mathrm{Co}(\mathrm{DTB})_{3}{ }^{2+}$

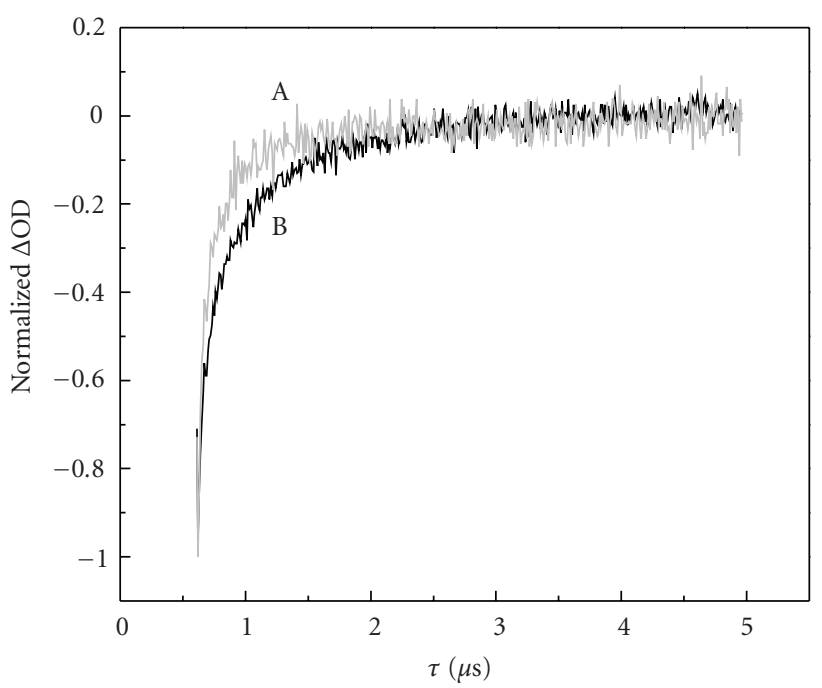

A: TBAI

B: $\mathrm{Co}(\mathrm{DTB})_{3}{ }^{2+}+\mathrm{LiClO}_{4}$

(b)

FIGURE 10: $480 \mathrm{~nm} \mathrm{Ru}(\mathrm{III})\left(\mathrm{H}_{2} \mathrm{DCB}\right)_{2}(\mathrm{NCS})_{2}^{+}$recovery in the presence of (a) Tetrabutyl-ammonium iodide $(\mathrm{A})$ and Co(DTB $)_{3}^{2+}(\mathrm{B}) 0.1 \mathrm{M}$; (b) Tetrabutyl-ammonium iodide $(\mathrm{A})$ and $\mathrm{Co}(\mathrm{DTB})_{3}^{2+}$ (B) $0.1 \mathrm{M}+\mathrm{LiClO}_{4} 0.1 \mathrm{M}$. Pulse energy $\approx 1 \mathrm{~mJ} / \mathrm{cm}^{2}$.

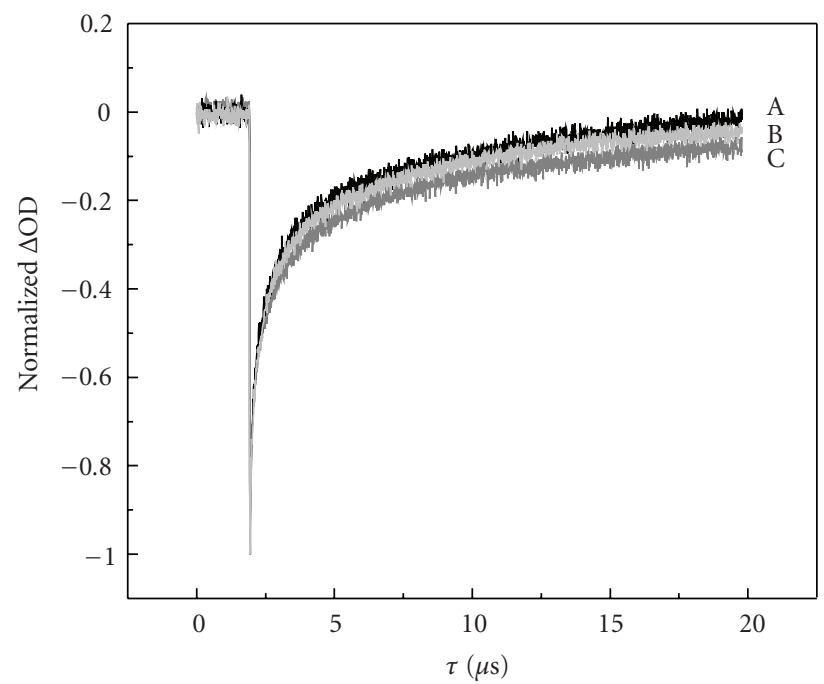

A: Neat solvent

B: $\mathrm{Co}(\mathrm{DTB})_{3}{ }^{2+}$

C: $\mathrm{TBAI}_{3}$

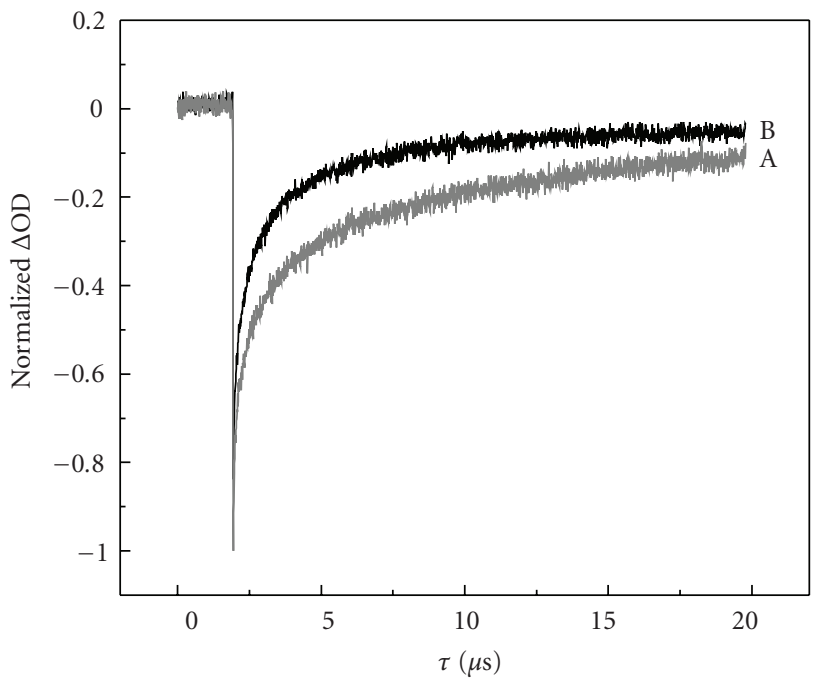

A: $\left[\mathrm{Co}(\mathrm{bpy})_{3}\right]^{3+}$

B: $\left[\mathrm{Co}(\mathrm{DTB})_{3}\right]^{3+}$

FIgURE 11: $480 \mathrm{~nm} \mathrm{Ru}(\mathrm{III})\left(\mathrm{H}_{2} \mathrm{DCB}\right)_{2}(\mathrm{NCS})_{2}^{+}$recovery in the presence of (a) neat solvent ( $\gamma$ butyrolactone) $(\mathrm{A}), 0.1 \mathrm{M} \mathrm{Co}(\mathrm{DTB})_{3}^{3+}(\mathrm{C})$, and Tetrabutyl-ammonium triiodide $(\mathrm{B}) ;(\mathrm{b}) \mathrm{Co}(\mathrm{DTB})_{3}^{3+}(\mathrm{B})$ and $\mathrm{Co}(\mathrm{bpy})_{3}^{3+}(\mathrm{A})$. Pulse energy $\approx 1 \mathrm{~mJ} / \mathrm{cm}^{2}$.

their redox potential is appropriate (i.e., more positive than the $\mathrm{Co}(\mathrm{III}) /(\mathrm{II})$ couple), a cascade of electron transfer events allows to confine the hole on $\mathrm{Co}$ (III) (Figure 12) which, by virtue of its very slow heterogeneous electron transfer on semiconductor oxides, gives rise to a very inefficient electron recapture. As a consequence, the large majority of $\mathrm{Co}$ (III) created in the second electron transfer step is free to diffuse to the counter electrode of the cell, whereupon it is reduced.
The use of a long alkyl chain dyes like Z907, for example, is beneficial to the system allowing to further reduce back recombination enhancing the electron collection efficiency.

Phenothiazine (PTZ) and ferrocene (Fc), both having a small reorganization energy associated to the electron transfer, are the first comediators that have been considered. Each has a potential which falls between that of the $\mathrm{Co}(\mathrm{DTB})_{3}^{3+/ 2+}(0.22 \mathrm{~V}$ versus $\mathrm{SCE})$ and of the 


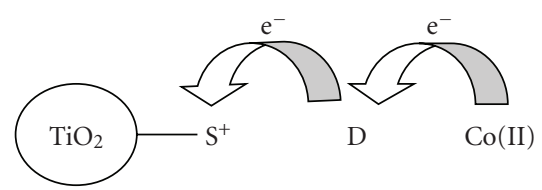

Figure 12: Sequence of electron transfer events involving the oxidized dye $\left(\mathrm{S}^{+}\right)$the comediator (D) and the cobalt complex (Co(II)).

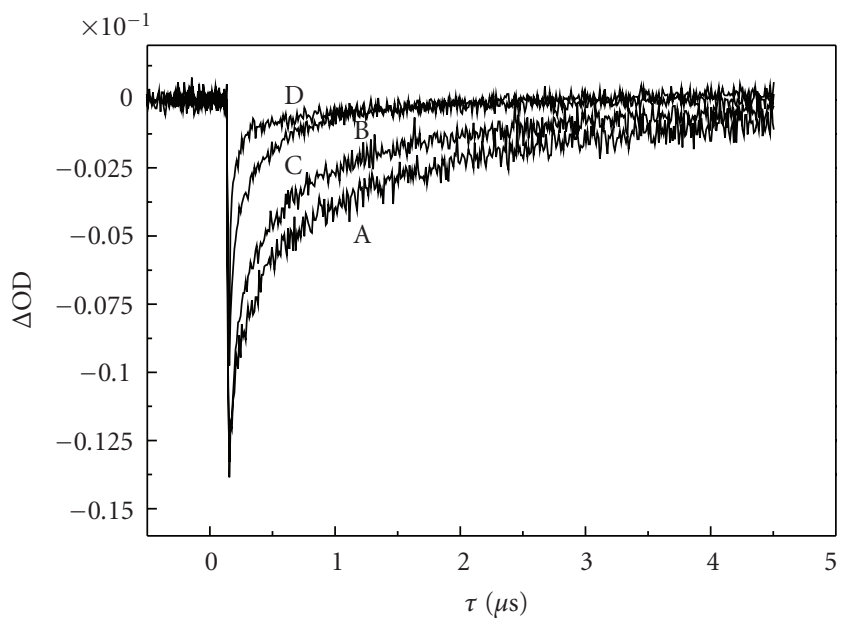

Figure 13: Decay kinetic of photooxidized Z907 adsorbed on $\mathrm{TiO}_{2}$ in the presence of various electron mediators: (A) no mediator; (B) $0.1 \mathrm{M} \mathrm{Co}(\mathrm{DTB})_{3}^{2+}$; (C) $0.1 \mathrm{M} \mathrm{PTZ;} \mathrm{(D)} 0.1 \mathrm{M} \mathrm{Fc}$. Differential absorbance changes are measured at $480 \mathrm{~nm}$. Pulse energy: $5 \mathrm{~mJ} / \mathrm{cm}^{2}$.

dye $\left[\mathrm{Ru}\left(\mathrm{H}_{2} \mathrm{DCB}\right)(\text { dnbpy })(\mathrm{NCS}) 2\right]^{+/ 0}(0.75 \mathrm{~V}$ versus $\mathrm{SCE})$. Because of the facile electron transfer the photooxidized dye would be predominantly reduced by the comediator. Its oxidized form $\left(\mathrm{PTZ}^{+}\right.$and $\mathrm{Fc}^{+}$) can be then rapidly intercepted by $\mathrm{Co}(\mathrm{II})$, preventing the direct charge recombination between the oxidized comediator and the electrons in the $\mathrm{TiO}_{2}$. Nanosecond transient absorption measurements confirmed a faster dye regeneration by both PTZ and Fc relative to $\mathrm{Co}(\mathrm{DTB})_{3}^{2+}$, despite their higher redox potential (Figure 13).

The best results were observed using a comediator/Co(II) ratio of $1: 2$ with $0.15 \mathrm{M} \mathrm{Co}(\mathrm{DTB})_{3}^{2+}$ in acetonitrile. Addition of $0.5 \mathrm{M} \mathrm{Li}^{+}$and $0.1 \mathrm{M}$ ter-butyl-pyridine generally improved the open circuit photovoltage. In the presence of the PTZ/Co(II) mixture cell IPCE\% reached more than $80 \%$ (Figure 14(b)), a value well comparable to the best $\mathrm{I}_{3}^{-} / \mathrm{I}^{-}$ cells. Under white light irradiation $J_{\mathrm{sc}}$ was also comparable, with the advantage of a better fill factor and higher Voc for the cobalt-based cell (Figure 14(a)).

In general the $\mathrm{Fc} / \mathrm{Co}(\mathrm{II})$ mixture gave poorer overall photovoltaic performances than the equivalent PTZ/Co(II) system, notably a poorer Voc and fill factor. Since ferrocene was found to be faster in dye regeneration, an explanation can lie in a less efficient interception of $\mathrm{Fc}^{+}$by $\mathrm{Co}$ (II) centres, resulting in a larger steady state concentration of $\mathrm{Fe}(\mathrm{III})$ which undergoes recombination on the $\mathrm{TiO}_{2}$ surface. Indeed, chronocoulometry and cyclic voltammety experiments at FTO electrodes allowed to verify that $\mathrm{PTZ}^{+}$was from 1.5 to 2 times more effective than $\mathrm{Fc}^{+}$in the oxidation of $\mathrm{Co}(\mathrm{II})$, thus having a smaller probability of recombining with photoinjected electrons.

An analogous behaviour extends to other species having small reorganization energies and appropriate potentials such as the iron(II) complexes $\mathrm{Fe}(\mathrm{DMB})_{3}^{2+}$ and $\mathrm{Fe}(\mathrm{DTB})_{3}^{2+}$ $\left(E_{1 / 2} \approx 0.95 \mathrm{~V}\right.$ versus SCE). When used in the presence of an excess of $\mathrm{Co}(\mathrm{DTB})_{3}^{2+}$ and in conjunction with suitable sentizers like the heteroleptic dye $\mathrm{Ru}($ dnbpy $)\left(\mathrm{H}_{2} \mathrm{DCB}\right)_{2}^{2+}$ $\left(E_{1 / 2}=1.25 \mathrm{~V}\right.$ versus SCE) (Figure 15) the $\mathrm{Fe}(\mathrm{II})$ comediators clearly enhance the performance of the $\mathrm{Co}(\mathrm{DTB})_{3}^{2+}$ and outperform the $\mathrm{I}_{3}^{-} / \mathrm{I}^{-}$redox couple, at least in terms of IPCE, with maximum values close to $85 \%$.

Interestingly, the polypyridine $\mathrm{Fe}(\mathrm{II}) / \mathrm{Co}(\mathrm{II})$ mediator mixtures were rather insensitive to variations of the $\mathrm{Fe}$ (II) to $\mathrm{Co}$ (II) concentration ratio ranging from 0.1 to 0.5 , with the optimum at 0.1 . For higher $\mathrm{Fe}(\mathrm{II}) / \mathrm{Co}$ (II) ratios the cell performance dropped, ostensibly due to the formation of an excess of $\mathrm{Fe}(\mathrm{III})$ which was no longer effectively intercepted by $\mathrm{Co}(\mathrm{II})$ and recombined on the $\mathrm{TiO}_{2}$ surface. In the case of electron mediator mixtures characterized by the presence of a kinetically fast couple, the decrease in $\zeta$ potential and the blocking effect obtained by using heteroleptic dyes with hindering chains is more than ever important for controlling electron recapture: meaningfully, the performances of the $\mathrm{Fe}(\mathrm{II}) / \mathrm{Co}(\mathrm{II})$ mixtures used in conjunction with the homoleptic $\mathrm{Ru}\left(\mathrm{H}_{2} \mathrm{DCB}\right)_{3}^{2+}$ (where DCB is the $4,4^{\prime}$ dicarboxylic acid 2,2' bipyridine) were rather poor, not exceeding a maximum IPCE\% of $30 \%$, whereas the $\mathrm{I}_{3}^{-} / \mathrm{I}^{-}$ couple produced almost identical conversions (ca. 40\%) to those reported with the heteroleptic $\mathrm{Ru}(\mathrm{dnbpy})\left(\mathrm{H}_{2} \mathrm{DCB}\right)_{2}^{2+}$.

The $\mathrm{Fe}(\mathrm{II}) / \mathrm{Co}(\mathrm{II})$ mediators displayed an interesting behaviour in conjunction with bisterpyridine complexes (formula in Figure 16) which, when used with the $\mathrm{I}^{-} / \mathrm{I}_{2}$ couple, have been known to be rather poor sensitizers. The IPCE $\%$ improved from the $20 \%$ obtained in the presence of $\mathrm{LiI} / \mathrm{I}_{2}$ to $30 \%$ with $\mathrm{Co}(\mathrm{DTB})_{3}^{2+}$ alone, to more than $60 \%$ using the $\mathrm{Fe}(\mathrm{DMB})_{3}^{2+} / \mathrm{Co}(\mathrm{DTB})_{3}^{2+}$ system (Figure 16).

Spectroscopic investigation evidenced that this enhanced performance could not be explained by an improved dye regeneration by the cobalt-based mediators: despite giving rise to an efficient dye recovery ( $14 \mathrm{~ns}$ and $9 \mathrm{~ns}$ for the $\mathrm{Co}$ (II) and the $\mathrm{Fe}(\mathrm{II}) / \mathrm{Co}(\mathrm{II})$ mixture, resp.) these metal-based mediators were still slower than iodide, which produced an instrument response-limited ( $\leq 7 \mathrm{~ns}$ ) $\mathrm{Ru}$ (II) regeneration. Further investigations indicated, however, that the oxidized form of the iodide-based mediator, namely, triiodide, was consistently more effective than $\mathrm{Co}$ (III) in capturing conduction band electrons, producing a notable increase in the $\mathrm{Ru}$ (III) lifetime (Figure 17).

Thus the relatively low IPCE\% observed with $\mathrm{I}_{3}^{-} / \mathrm{I}^{-}$ appeared to be essentially determined by an efficient electron recombination with triiodide. This phenomenon, surprising at first, could be caused by a number of factors ranging 


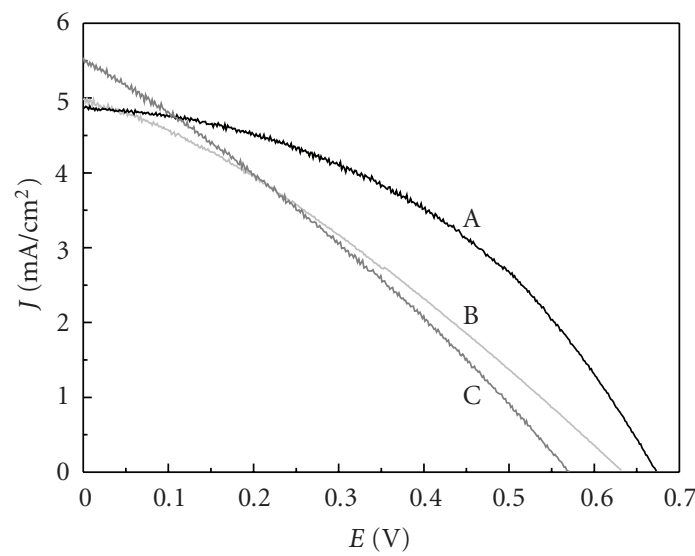

(a)

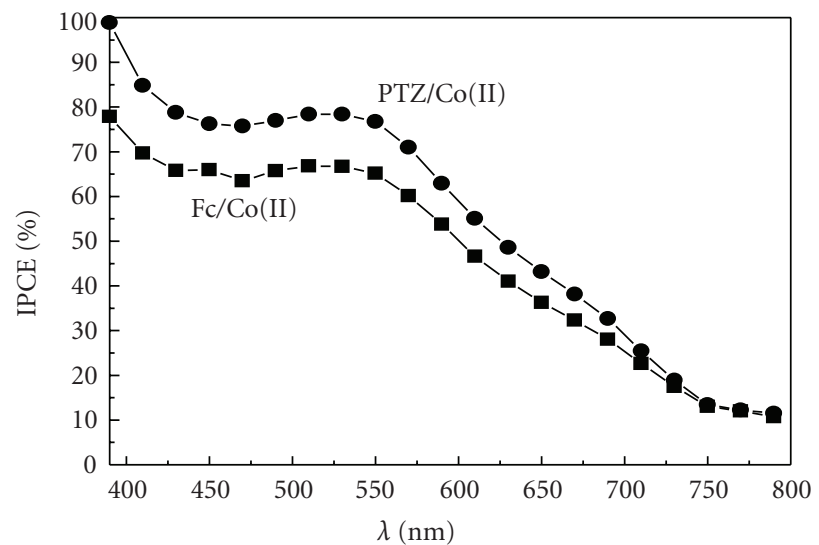

(b)

Figure 14: (a) J-V curves obtained in the presence of $\mathrm{Co}(\mathrm{II}) / \mathrm{PTZ}(\mathrm{A}), \mathrm{I}_{3}^{-} / \mathrm{I}^{-}$(B), and $\mathrm{Co}(\mathrm{II}) / \mathrm{Fc}(\mathrm{C})$ in methoxypropionitrile. (b) Photoaction spectra. Incident irradiance $\approx 0.1 \mathrm{~W} / \mathrm{cm}^{2}$.
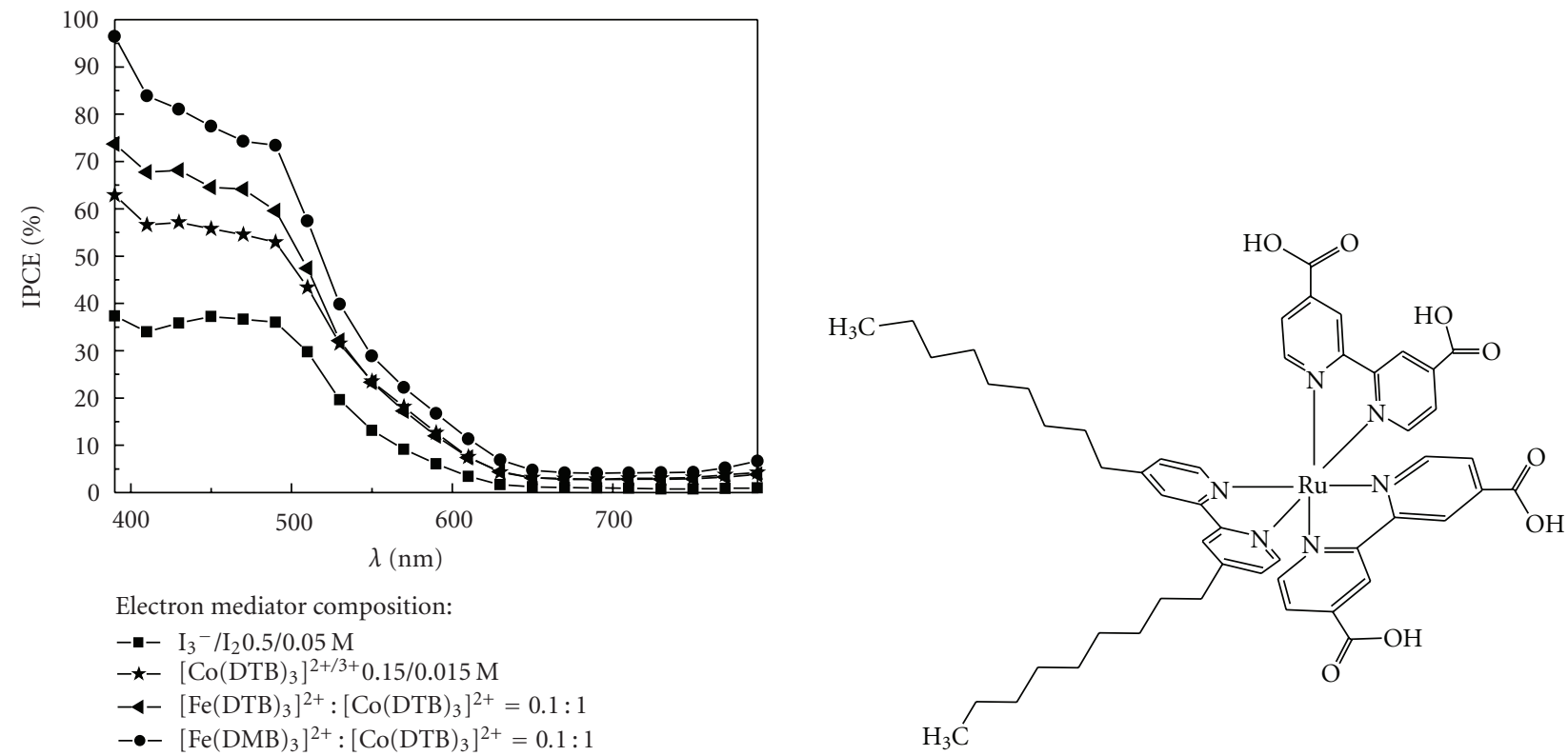

Figure 15: IPCE spectra of $\mathrm{Ru}(\mathrm{dnbpy})\left(\mathrm{H}_{2} \mathrm{DCB}\right)_{2}^{2+}$ obtained in the presence different electron transfer mediators.

from an insufficient $\mathrm{TiO}_{2}$ surface passivation by the dye against the small $\mathrm{I}_{3}^{-}$ions, to specific interactions between the complex and $\mathrm{I}_{3}^{-}$which lead to iodine association via the sulphur atom of the thiophene ring and to the induction of a positive surface charge upon adsorption of the cationic $\mathrm{Ru}$ (II) dye possessing only one carboxylic function. The positively charged surface might attract $\mathrm{I}_{3}^{-}$favouring recombination and, on the contrary, might repel $\mathrm{Co}$ (III), ultimately reducing the probability of electron recapture in the latter case. Thus it seems that, depending on their structure and charge, each dye interacts specifically with different electron mediators in ways that are worth to be studied, since they may lead to both fundamental and practical advances in DSSC design in the future.

\section{Solid State Conductive Polymers}

Conductive polymers based on polythiophenes and polypyrroles could be interesting candidates for replacing the liquid electrolyte in DSSC, due to their low cost, thermal stability, and good conductivity [48]. Thanks to these properties, these systems have already found application in the OLED technology as charge transporting matrices. PEDOP (poly-ethylene-dioxy-pyrrole) can be deposited on a sensitized $\mathrm{TiO}_{2}$ photoanode via a photoassisted electropolymerization [49] initiated by the purpose built ruthenium complex $\left[\mathrm{Ru}\left(\mathrm{H}_{2} \mathrm{DCB}\right)(\text { pyrr-bpy })_{2}\right]^{2+} \quad[50]$ (Figure 18): the oxidized dye, $\left[\mathrm{Ru}^{\mathrm{III}}\left(\mathrm{H}_{2} \mathrm{DCB}\right) \text { (pyrr-bpy) }{ }_{2}\right]^{3+}$, created after the charge injection into $\mathrm{TiO}_{2}$, is a sufficiently 


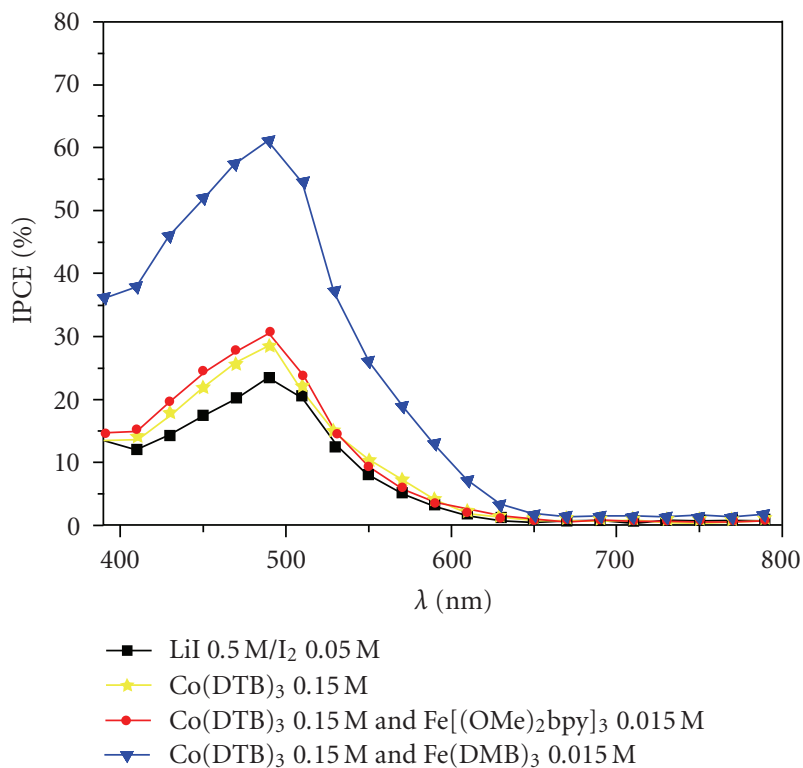

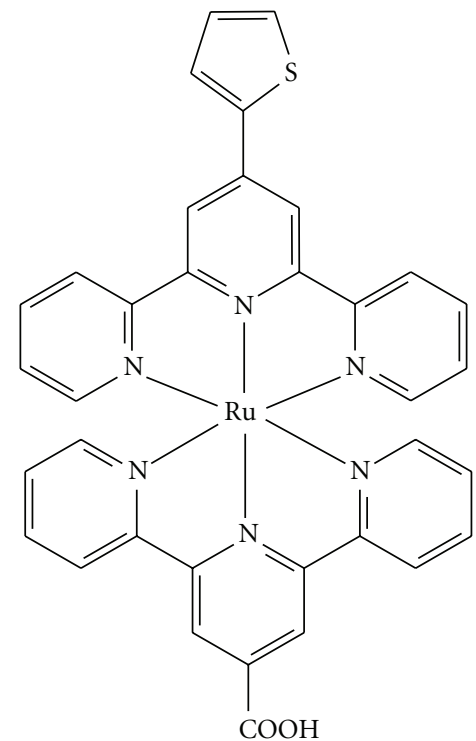

FIGURE 16: IPCE spectra in the presence of various electron mediators obtained by using the $\left[\mathrm{Ru}(\mathrm{II})(\text { terpy)}(\mathrm{Thpterpy})]^{2+} \mathrm{dye}\right.$ as a TiO ${ }_{2}$ photosensitizer. Thpterpy stands for the 4 '-thiophene terpyridine.

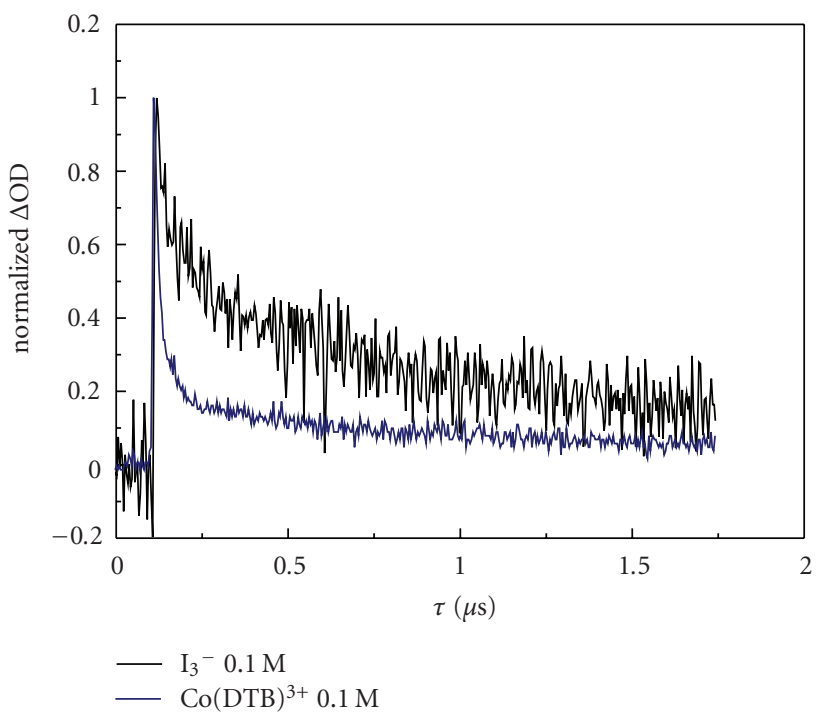

Figure 17: Differential absorption decays for $\mathrm{Ru}(\mathrm{III})$ recovery observed at $750 \mathrm{~nm}$ in the presence of equimolar amounts of $\mathrm{I}_{3}^{-}$ and $\mathrm{Co}(\mathrm{III})$ in acetonitrile $+0.5 \mathrm{M} \mathrm{Li}^{+}$. Excitation energy density $\approx 1 \mathrm{~mJ} / \mathrm{cm}^{2} /$ pulse.

strong oxidizer, with a potential of $1.19 \mathrm{~V} / \mathrm{SCE}$, to oxidize EDOP monomers and induce their cationic polymerization, leading to the growth of polymeric chains chemically attached to the dye with a possible advantage in terms of electronic coupling and charge transfer rate between electron donor (PEDOP) and acceptor (oxidized dye).

A typical solar cell assembled according to this approach is comprised of a photoanode, functionalized with PEDOP, firmly clamped together with a gold-coated FTO counter electrode. A $0.3 \mathrm{M} \mathrm{LiClO}_{4}$ solution in $\gamma$-butyrolactone is eventually drawn inside the cell by capillarity.

Our results on these types of cells showed very low efficiencies mostly due to small $J_{\mathrm{sc}}(<200 \mu \mathrm{A})$ and poor fill factors $(\leq 0.31)$. The J-V characteristics of solid state PEDOP cells (Figure 19) indicate a strong recombination and a high serial resistance.

Dark current measurements performed under direct voltage bias showed a marked increase in recombination efficiency as the bias approached $-0.4 \mathrm{~V}$, near the onset of PEDOP reduction, suggesting that higher lying states of $\mathrm{TiO}_{2}$ were filled promoting recombination with PEDOP holes.

While the dark current suggested a possible photocurrent loss mechanism through PEDOP reduction, a relevant recombination with the oxidized dye could not be ruled out. Dark current simply could not provide information on the latter process since, in the dark, after equilibrium was attained, no oxidized $\mathrm{Ru}$ (III) centres should be present at the $\mathrm{TiO}_{2} /$ Dye/polymer interface.

Indications of efficient recombination were also gained from cell photocurrent transients under short circuit conditions, showing cathodic spikes due to recombination of photoinjected electrons with PEDOP holes and oxidized $\mathrm{Ru}(\mathrm{III})$ centres.

The cathodic current dropped to zero on a very short time scale suggesting that recombination was kinetically fast, at least for the time scale $(0.1 \mathrm{~s}$ sampling time) of the experiment. Passivation of the $\mathrm{TiO}_{2}$ surface via the application of a nanometric insulating $\mathrm{Al}_{2} \mathrm{O}_{3}$ overlayer [51] was instrumental in reducing the electronic recapture, allowing for an IPCE\% doubling (from 3\% to 6\%) (Figure 20). Cell Jsc and Voc measured under $0.05 \mathrm{~W} / \mathrm{cm}^{2}$ white light irradiation were also significantly improved (from 50 to $100 \mu \mathrm{A} / \mathrm{cm}^{2}$ and from 0.4 to $0.7 \mathrm{~V}$, resp.). 


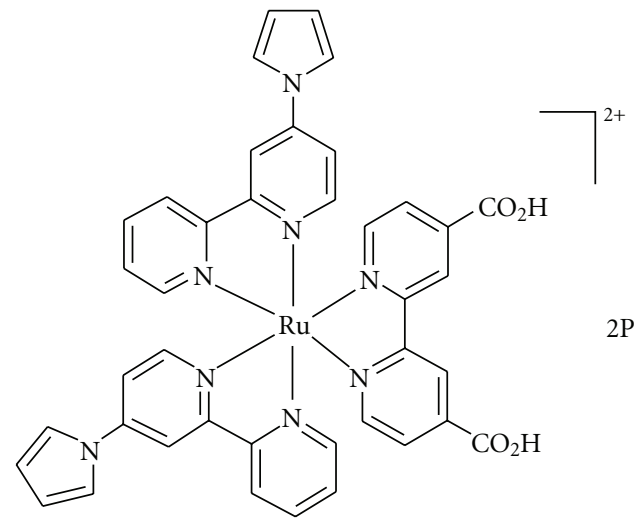<smiles>c1ccc(-c2cc(-n3cccc3)ccn2)nc1</smiles>

$2 \mathrm{PF}_{6}{ }^{-}$

Pyrr-bpy $=$

$\left[\mathrm{Ru}\left(\mathrm{H}_{2} \mathrm{DCB}\right)(\text { pyrr-bpy })_{2}\right]^{2+}$

FIgURE 18: $\mathrm{Ru}(\mathrm{II})$ complex uses for in situ photoassisted PEDOP growth.

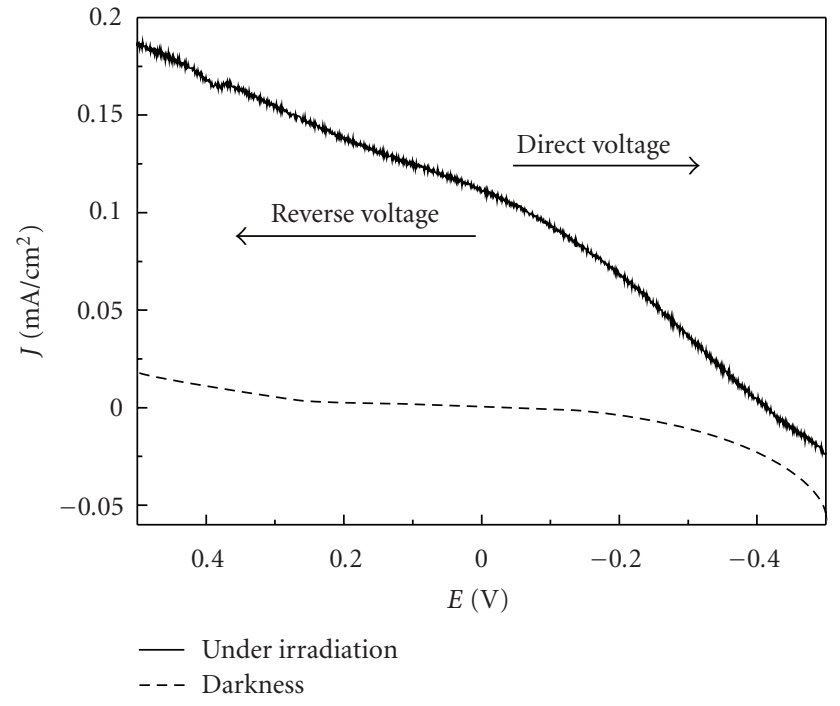

FIgURE 19: J-V characteristic obtained on PEDOP-based DSSC in the presence of $\mathrm{Li}^{+} 0.3 \mathrm{M} .10$ seconds polymerization time.

Besides strong back recombination and despite the intimate contact between the dye and the hole transporting layer, the low efficiencies could also be explained by a nonoptimal hole injection into the PEDOP matrix, as evidenced by the slow oxidized dye recovery observed in transient absorbance experiments at $450 \mathrm{~nm}$.

A better photovoltaic response has been recently obtained by using the excellent properties of PEDOT as a hole transporting material. As previously described, PEDOT can be in situ photo-electropolymerized from bis-EDOT monomers by exploiting the oxidizing power of a dye like Z907 [52]. The hydrophobic properties of Z907 allow for a good affinity for the scarcely polar polymeric matrix, ensuring a good electrical contact between the p-type material and the dye. The presence of

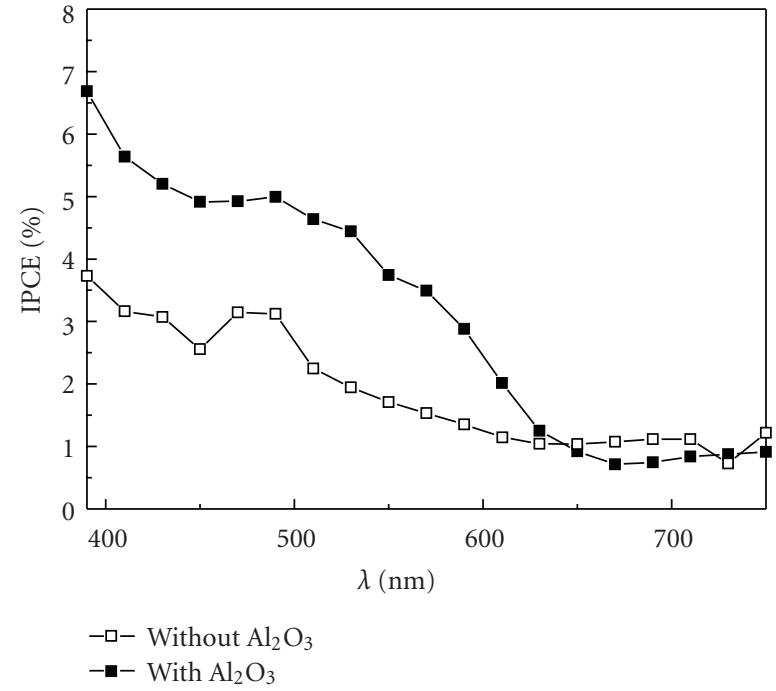

Figure 20: Photoaction spectra of a $\mathrm{TiO}_{2} / \mathrm{Dye} / \mathrm{PEDOP} / \mathrm{Au}$ cell (white squares) compared to a $\mathrm{TiO}_{2} / \mathrm{Al}_{2} \mathrm{O}_{3} /$ Dye/PEDOP/Au system (black squares).

a coadsorbate like deoxycholic acid (DCA) in an optimal $2: 1$ ratio with respect to the dye enhanced the global photovoltaic response by reducing dye aggregates. This function seems to be particularly relevant for polymer mediated DSSC, since aggregated dye clusters reduce the number of available polymer growth sites and leave less effective space for polymerization initiation and propagation. In order to optimize the contact between the hole transporting layer and the counter electrode, a PEDOTfunctionalized FTO was used as the cathode and, to achieve optimal performances, a drop of BMImTFSI (1-butyl3 methylimidazolium bis(trifluoromethanesulfonyl)imide) containing $0.2 \mathrm{M}$ LiTFSI and $0.2 \mathrm{M}$ Tbpy was cast onto the $\mathrm{TiO}_{2}$ /dye/PEDOP junction. The ionic liquid may improve the charge transporting capabilities of the heterointerface 


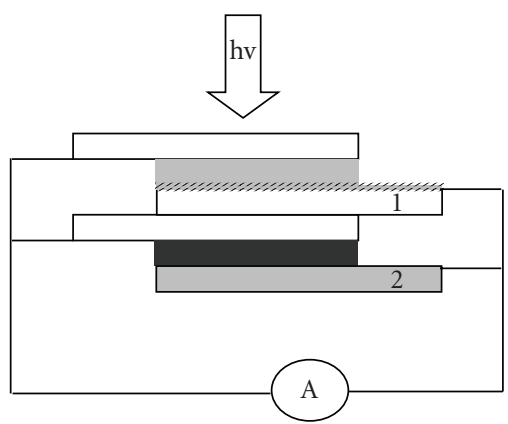

Figure 21: In parallel connected stacked cell based on the $\mathrm{Co}(\mathrm{II}) /(\mathrm{III})$ couple. 1 is a transparent FTO cathode modified via chemisorption of an electroactive molecule. 2 is a conventional gold cathode. The red and the blue dyes, absorbing in complementary spectral regions, result in a panchromatic sensitization.

through screening of space charge effects, lithium cations assist electron injection and percolation through the n-type semiconductor, and, as usual, tbpy increases the open circuit photovoltage via suppression of the back recombination. With such a treatment $\mathrm{FTO} / \mathrm{TiO}_{2} /$ dye/PEDOT-PEDOT/FTO sandwich cells afforded efficiencies of the order of $2.6 \%$, one of the highest results so far recorded with solid state DSSCs based on hole conducting polymers.

\section{Catalytic Materials for Cathodes of DSSCs}

A kinetically fast reduction of the oxidized redox mediator at the cathodic surface of the cell is required to maintain a sufficiently high concentration of electron donor thus ensuring an efficient dye regeneration. With the $\mathrm{I}_{3}^{-} / \mathrm{I}^{-}$couple the use of a catalytic platinum coating is almost mandatory to achieve a satisfactory electrochemical kinetics, but the use of redox mediators alternative to the $\mathrm{I}_{3}^{-} / \mathrm{I}^{-}$couple opens the way to the search for new, less expensive, more flexible, and available catalytic materials and to their application in new cell configurations. Many electrode materials (carbon, gold, platinum) function adequately in the case of $\mathrm{Co}(\mathrm{II}) /(\mathrm{III})$ mediators but are generally opaque. In contrast, optically transparent conductive oxides (TCOs) are very poor cathodes for the $\mathrm{Co}(\mathrm{DTB})_{3}^{2+/ 3+}$ couple, unless they are chemically modified by surface chemisorption of certain metal complexes. This allows to obtain optically transparent cathodes with a good electrochemical response which can be employed to build stacked cells either serially or in parallel (Figure 21) connected in which, for example, two spectrally complementary dye can work in their optimal absorption region, improving the spectral responsivity of the modules.

In a first study [53] it was demonstrated that ITO and FTO electrodes modified by irreversibly adsorbing a monolayer of $\mathrm{Fe}\left(\mathrm{H}_{2} \mathrm{DCB}\right)_{3}^{2+}$ electrocatalyze efficiently the $\mathrm{Co}(\mathrm{DTB})_{3}^{2+}$ oxidation via an $\mathrm{EC}^{\prime}$ mechanism. However, while electrogenerated $\mathrm{Fe}(\mathrm{III})$ has an ample driving force for oxidizing $\mathrm{Co}(\mathrm{II}), \mathrm{Fe}(\mathrm{II})$ is a thermodynamically too weak reductant for catalyzing Co(III) reduction, and the

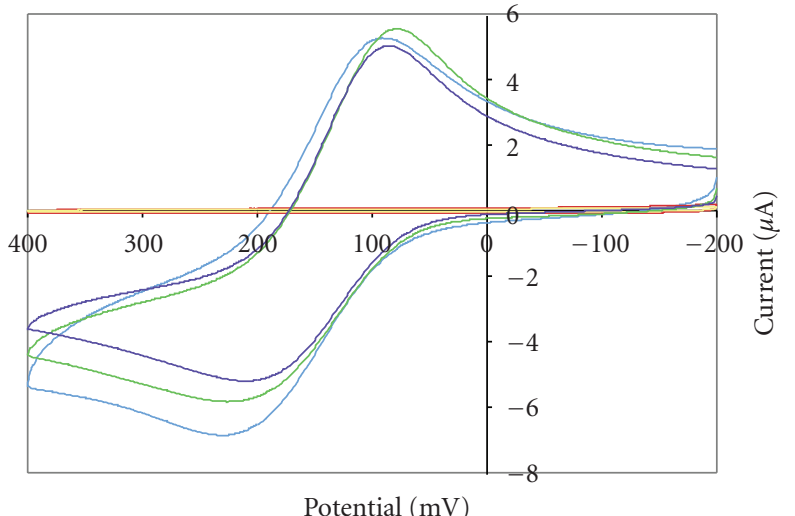

Figure 22: CV on gold (A), FTO (B), ITO (C), and osmium modified FTO (D) and ITO (E) working electrodes in the presence of ca. $0.1 \mathrm{mM} \mathrm{Co}(\mathrm{DTB})_{3} \mathrm{ClO}_{4}$. Potential referred to ferrocene.

$\mathrm{Fe}(\mathrm{II}) /(\mathrm{III})$ couple is of no value for building transparent cathodes.

Nevertheless it was found that the electrocatalysis of the $\mathrm{Co}(\mathrm{II}) /(\mathrm{III})$ redox chemistry promoted by surface bound electroactive species is a relatively general phenomenon and a number of molecular species with appropriate potential can promote the desired catalytic effect. For example, the osmium complex $\mathrm{Os}\left(\mathrm{H}_{2} \mathrm{DCB}\right)_{2} \mathrm{Cl}_{2}$ can be strongly adsorbed on FTO and, with its potential ( $-310 \mathrm{mV}$ versus Ferrocene) slightly negative of the $\mathrm{Co}$ (II)/(III) couple, proved to efficiently catalyze both the oxidation and reduction of $\mathrm{Co}(\mathrm{DTB})_{3}^{2+/ 3+}$. Indeed, the cyclic voltammetry of $\mathrm{Co}(\mathrm{II}) /(\mathrm{III})$ (Figure 22) recorded at osmium-modified electrodes showed well-defined quasireversible waves $(\triangle E p \approx 140 \mathrm{mV})$, nearly identical to those obtained on gold, whereas on the unmodified FTO or ITO it was almost impossible to observe the analogous charge transfer process. Cyclic voltammetry results were substantially confirmed by thin layer photoelectrochemical experiments which demonstrated that the osmium-modified transparent cathodes gave rise to a very small overpotential (ca. $12 \mathrm{mV}$ under cell short circuit conditions) for $\mathrm{Co}$ (III) reduction, indicative of a facile heterogeneous electron transfer [54].

The stacked cell configuration, employing N3 and a red absorbing cyanine dye which absorbs photons in a region where N3 does not, showed a $J_{\text {sc }}$ improvement of about $15 \%$ over a single N3 cell. It must be considered that the blue dye is relatively inefficient, generating very modest IPCE\% (ca. 5\%-8\%) due to less than ideal redox properties and electronic coupling with the $\mathrm{TiO}_{2}$. Nevertheless the results confirmed the principle and with a better performing dye substantial performance improvements are expected.

Conductive polymers like PEDOP and PEDOT were also found effective in promoting the $\mathrm{Co}(\mathrm{II}) /(\mathrm{III})$ electrochemical response. Both PEDOP and PEDOT can be electrodeposited on a transparent conductive substrate by an anodic potentiostatic (ca. $+1.3 \mathrm{~V}$ versus $\mathrm{SCE}$ ) or potentiodynamic electrolysis of the appropriate precursor solution in the presence of a perchlorate containing supporting electrolyte. $\mathrm{Co}(\mathrm{II}) /(\mathrm{III})$ 


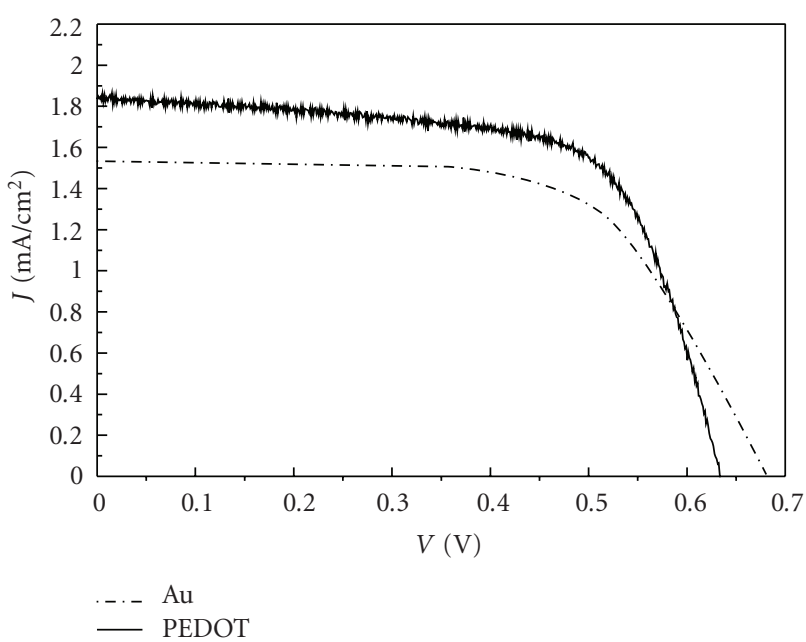

Figure 23: J-V curves of $\mathrm{Co}(\mathrm{II}) /(\mathrm{III})$-mediated cell employing a gold (dashed line) and a PEDOT counter electrode (solid line). Electrolyte composition is $0.15 \mathrm{M} \mathrm{Co}(\mathrm{II}) / 0.5 \mathrm{M} \mathrm{Li}^{+} / 0.1 \mathrm{M}$ Tbpy in acetonitrile. Cell is equipped with a $120 \mu \mathrm{m}$ spacer. Photosensitizer Z907.

appeared to have a clearly diffusion-limited electrochemical behaviour on both PEDOP- and PEDOT- functionalized cathodes. PEDOT gave rise to a more ideal behaviour associated to a smaller separation of the catalytic waves, with a peak separation of the order of $200 \mathrm{mV}$, substantially independent from $\mathrm{Co}$ (II) concentration, the slight peak shift at higher cobalt concentration being essentially determined by uncompensated cell resistance.

The electrodeposition offers the advantage of a fine control of the thickness of the catalytic layer, thus optimizing the electroactive area and the transparency of the cathode. A cathode which possesses both a remarkable catalytic activity and a partially porous structure with a large active area is important for limiting the concentration overpotential which may develop at the counter electrode of the cell under strong illumination, allowing for the consequent reduction of the photocell series resistance. An improvement in cell fill factor and global efficiency is therefore expected and found (Figure 23).

\section{Conclusions}

DSSCs are photoelectrochemical solar devices, currently subject of intense research in the framework of renewable energies as a low-cost photovoltaic device.

Researches on dye sensitizers are mainly focused on transition metal complexes, but a considerable amount of work is now directed towards the optimization of organic sensitizers and of natural sensitizers extracted from fruits.

Concerning the electron mediators, iodide/iodine has been so far the most efficient and commonly used redox system, due to the fact that $\mathrm{I}^{-}$allows for a fast regeneration of the oxidized dye. The use of alternative redox couples as electron mediators has been addressed, so far, by a limited number of research groups but the results are promising.
To date, the most successful attempts have been based on octahedral cobalt(II) complexes and the best results obtained in combination with specific heteroleptic complexes. The development of efficient and noncorrosive electron mediators is considered of particular relevance since it may allow building large area modules where the different components are in parallel interconnected, increasing the single module short circuit photocurrent and allowing for a more flexible solar panel production.

The search for suitable solid materials that can replace the liquid electrolyte is an additional interesting and active area of research. Organic hole conductors like conductive polymers based on polythiophenes and polypyrroles have demonstrated some promise for application in dye-sensitized solar cells. In particular it has been reported that the presence of ionic liquids may improve the charge transporting capabilities of the heterointerface through screening of space charge effects.

Some efforts towards the modification of the counter electrode with inexpensive and transparent conductive materials have been discussed. In these studies it has been found that osmium complexes as well as electrodeposited conductive polymers like PEDOP an PEDOT are effective in promoting the electrochemical response of $\mathrm{Co}$ (II) electron mediators.

\section{Acknowledgment}

Financial support from the Polo Solare Organico, CHOSE, Regione Lazio is gratefully acknowledged.

\section{References}

[1] R. Memming, "Electron transfer processs with excited molecules at semiconductor electrodes," Progress in Surface Science, vol. 17, no. 1, pp. 7-73, 1984.

[2] B. O’Regan and M. Grätzel, "A low-cost, high-efficiency solar cell based on dye-sensitized colloidal $\mathrm{TiO}_{2}$ films," Nature, vol. 353, no. 6346, pp. 737-740, 1991.

[3] M. Grätzel, "Solar energy conversion by dye-sensitized photovoltaic cells," Inorganic Chemistry, vol. 44, no. 20, pp. 68416851, 2005.

[4] M. K. Nazeeruddin, P. Péchy, T. Renouard, et al., "Engineering of efficient panchromatic sensitizers for nanocrystalline $\mathrm{TiO}_{2}-$ based solar cells," Journal of the American Chemical Society, vol. 123, no. 8, pp. 1613-1624, 2001.

[5] C. Bauer, G. Boschloo, E. Mukhtar, and A. Hagfeldt, "Ultrafast studies of electron injection in $\mathrm{Ru}$ dye sensitized $\mathrm{SnO}_{2}$ nanocrystalline thin film," International Journal of Photoenergy, vol. 4, no. 1, pp. 17-20, 2002.

[6] Y. Fukai, Y. Kondo, S. Mori, and E. Suzuki, "Highly efficient dye-sensitized $\mathrm{SnO}_{2}$ solar cells having sufficient electron diffusion length," Electrochemistry Communications, vol. 9, no. 7, pp. 1439-1443, 2007.

[7] M. Quintana, T. Edvinsson, A. Hagfeldt, and G. Boschloo, "Comparison of dye-sensitized $\mathrm{ZnO}$ and $\mathrm{TiO}_{2}$ solar cells: studies of charge transport and carrier lifetime," Journal of Physical Chemistry C, vol. 111, no. 2, pp. 1035-1041, 2007.

[8] M. Saito and S. Fujihara, "Large photocurrent generation in dye-sensitized $\mathrm{ZnO}$ solar cells," Energy \& Environmental Science, vol. 1, pp. 280-283, 2008. 
[9] K. Sayama, H. Sugihara, and H. Arakawa, "Photoelectrochemical properties of a porous $\mathrm{Nb}_{2} \mathrm{O}_{5}$ electrode sensitized by a ruthenium dye," Chemistry of Materials, vol. 10, no. 12, pp. 3825-3832, 1998.

[10] A. Kay and M. Graetzel, "Artificial photosynthesis. 1. Photosensitization of $\mathrm{TiO}_{2}$ solar cells with chlorophyll derivatives and related natural porphyrins," The Journal of Physical Chemistry, vol. 97, no. 23, pp. 6272-6277, 1993.

[11] F. Odobel, E. Blart, M. Lagrée, et al., "Porphyrin dyes for $\mathrm{TiO}_{2}$ sensitization," Journal of Materials Chemistry, vol. 13, no. 3, pp. 502-510, 2003.

[12] M. K. Nazeeruddin, R. Humphry-Baker, M. Grätzel, et al., "Efficient near-IR sensitization of nanocrystalline $\mathrm{TiO}_{2}$ films by zinc and aluminum phthalocyanines," Journal of Porphyrins and Phthalocyanines, vol. 3, no. 3, pp. 230-237, 1999.

[13] J. He, A. Hagfeldt, S. E. Lindquist, et al., "Phthalocyaninesensitized nanostructured $\mathrm{TiO}_{2}$ electrodes prepared by a novel anchoring method," Langmuir, vol. 17, no. 9, pp. 2743-2747, 2001.

[14] W. Paw, S. D. Cummings, M. A. Mansour, W. B. Connick, D. K. Geiger, and R. Eisenberg, "Luminescent platinum complexes: tuning and using the excited state," Coordination Chemistry Reviews, vol. 171, no. 1, pp. 125-150, 1998.

[15] A. Islam, H. Sugihara, K. Hara, et al., "Dye sensitization of nanocrystalline titanium dioxide with square planar platinum(II) diimine dithiolate complexes," Inorganic Chemistry, vol. 40, no. 21, pp. 5371-5380, 2001.

[16] J. M. Rehm, G. L. McLendon, Y. Nagasawa, K. Yoshihara, J. Moser, and M. Grätzel, "Femtosecond electron-transfer dynamics at a sensitizing dye-semiconductor $\left(\mathrm{TiO}_{2}\right)$ interface," Journal of Physical Chemistry, vol. 100, no. 23, pp. 95779578, 1996.

[17] P. V. Kamat and W. E. Ford, "Photochemistry on surfaces: triplet-triplet energy transfer on colloidal $\mathrm{TiO}_{2}$ particles," Chemical Physics Letters, vol. 135, no. 4-5, pp. 421-426, 1987.

[18] S. Das, C. S. Rajesh, C. H. Suresh, et al., "Photophysical and photoelectrochemical behavior of poly[styrene-co-3(acrylamido)-6-aminoacridine]," Macromolecules, vol. 28, no. 12, pp. 4249-4254, 1995.

[19] D. Liu and P. V. Kamat, "Photoelectrochemical behavior of thin CdSe and coupled $\mathrm{TiO}_{2} / \mathrm{CdSe}$ semiconductor films," Journal of Physical Chemistry, vol. 97, no. 41, pp. 10769-10773, 1993.

[20] M. K. Nazeeruddin, A. Kay, I. Rodicio, et al., "Conversion of light to electricity by cis-Xbis $\left(2,2^{\prime}\right.$-bipyridyl- $4,4^{\prime}$ dicarboxylate)ruthenium(II) charge-transfer sensitizers (X = $\mathrm{Cl}, \mathrm{Br}, \mathrm{I}, \mathrm{CN}$, and SCN) on nanocrystalline $\mathrm{TiO}_{2}$ electrodes," Journal of the American Chemical Society, vol. 115, no. 14, pp. 6382-6390, 1993.

[21] G. Sauvé, M. E. Cass, G. Coia, et al., "Dye sensitization of nanocrystalline titanium dioxide with osmium and ruthenium polypyridyl complexes," Journal of Physical Chemistry B, vol. 104, no. 29, pp. 6821-6836, 2000.

[22] P. Wang, C. Klein, R. Humphry-Baker, S. M. Zakeeruddin, and M. Grätzel, "A high molar extinction coefficient sensitizer for stable dye-sensitized solar cells," Journal of the American Chemical Society, vol. 127, no. 3, pp. 808-809, 2005.

[23] A. Hagfeldt and M. Grätzel, "Molecular photovoltaics," Accounts of Chemical Research, vol. 33, no. 5, pp. 269-277, 2000.

[24] F. Cecchet, A. M. Gioacchini, M. Marcaccio, et al., "Solvent effects on the oxidative electrochemical behavior of cis-bis(isothiocyanato)ruthenium(II)-bis-2, $2^{\prime}$-bipyridine4, 4' -dicarb oxylic acid," Journal of Physical Chemistry B, vol. 106, no. 15, pp. 3926-3932, 2002.

[25] S. Altobello, R. Argazzi, S. Caramori, et al., "Sensitization of nanocrystalline $\mathrm{TiO}_{2}$ with black absorbers based on Os and Ru polypyridine complexes," Journal of the American Chemical Society, vol. 127, no. 44, pp. 15342-15343, 2005.

[26] C. W. Lee, H. P. Lu, C. M. Lan, et al., "Novel zinc porphyrin sensitizers for dye-sensitized solar cells: synthesis and spectral, electrochemical, and photovoltaic properties," Chemistry: A European Journal, vol. 15, no. 6, pp. 1403-1412, 2009.

[27] X.-F. Wang, O. Kitao, H. Zhou, H. Tamiaki, and S.-I. Sasaki, "Efficient dye-sensitized solar cell based on oxobacteriochlorin sensitizers with broadband absorption capability," Journal of Physical Chemistry C, vol. 113, no. 18, pp. 7954-7961, 2009.

[28] W. M. Campbell, K. W. Jolley, P. Wagner, et al., "Highly efficient porphyrin sensitizers for dye-sensitized solar cells," Journal of Physical Chemistry C, vol. 111, no. 32, pp. 1176011762, 2007.

[29] B. C. O’Regan, I. López-Duarte, M. V. Martínez-Díaz, et al., "Catalysis of recombination and its limitation on open circuit voltage for dye sensitized photovoltaic cells using phthalocyanine dyes," Journal of the American Chemical Society, vol. 130, no. 10, pp. 2906-2907, 2008.

[30] J.-H. Yum, P. Walter, S. Huber, et al., "Efficient far red sensitization of nanocrystalline $\mathrm{TiO}_{2}$ films by an unsymmetrical squaraine dye," Journal of the American Chemical Society, vol. 129, no. 34, pp. 10320-10321, 2007.

[31] C. G. Garcia, A. Sarto Polo, and N. Y. Murakami Iha, "Fruit extracts and ruthenium polypyridinic dyes for sensitization of $\mathrm{TiO}_{2}$ in photoelectrochemical solar cells," Journal of Photochemistry and Photobiology A, vol. 160, no. 1-2, pp. 87-91, 2003.

[32] G. Calogero and G. Di Marco, "Red Sicilian orange and purple eggplant fruits as natural sensitizers for dye-sensitized solar cells," Solar Energy Materials and Solar Cells, vol. 92, no. 11, pp. 1341-1346, 2008.

[33] T. A. Heimer, E. J. Heilweil, C. A. Bignozzi, and G. J. Meyer, "Electron injection, recombination, and halide oxidation dynamics at dye-sensitized metal oxide interfaces," Journal of Physical Chemistry A, vol. 104, no. 18, pp. 4256-4262, 2000.

[34] I. Montanari, J. Nelson, and J. R. Durrant, "Iodide electron transfer kinetics in dye-sensitized nanocrystalline $\mathrm{TiO}_{2}$ films," Journal of Physical Chemistry B, vol. 106, no. 47, pp. 1220312210, 2002.

[35] G. Schlichthörl, S. Y. Huang, J. Sprague, and A. J. Frank, "Band edge movement and recombination kinetics in dyesensitized nanocrystalline $\mathrm{TiO}_{2}$ solar cells: a study by intensity modulated photovoltage spectroscopy," Journal of Physical Chemistry B, vol. 101, no. 41, pp. 8141-8155, 1997.

[36] S. Y. Huang, G. Schlichthörl, A. J. Nozik, M. Grätzel, and A. J. Frank, "Charge recombination in dye-sensitized nanocrystalline $\mathrm{TiO}_{2}$ solar cells," Journal of Physical Chemistry B, vol. 101, no. 14, pp. 2576-2582, 1997.

[37] H. Nusbaumer, J. E. Moser, S. M. Zakeeruddin, M. K. Nazeeruddin, and M. Grätzel, "Co(dbbip) complex rivals triiodide/iodide redox mediator in dye-sensitized photovoltaic cells," Journal of Physical Chemistry B, vol. 105, no. 43, pp. 10461-10464, 2001.

[38] C. Klein, M. K. Nazeeruddin, D. Di Censo, P. Liska, and M. Grätzel, "Amphiphilic ruthenium sensitizers and their applications in dye-sensitized solar cells," Inorganic Chemistry, vol. 43, no. 14, pp. 4216-4226, 2004. 
[39] P. Wang, S. M. Zakeeruddin, P. Comte, R. Charvet, R. Humphry-Baker, and M. Grätzel, "Enhance the performance of dye-sensitized solar cells by Co-grafting amphiphilic sensitizer and hexadecylmalonic acid on $\mathrm{TiO}_{2}$ nanocrystals," Journal of Physical Chemistry B, vol. 107, no. 51, pp. 1433614341, 2003.

[40] S. A. Sapp, C. M. Elliott, C. Contado, S. Caramori, and C. A. Bignozzi, "Substituted polypyridine complexes of cobalt(II/III) as efficient electron-transfer mediators in dyesensitized solar cells," Journal of the American Chemical Society, vol. 124, no. 37, pp. 11215-11222, 2002.

[41] T. N. Murakami, S. Ito, Q. Wang, et al., "Highly efficient dye-sensitized solar cells based on carbon black counter electrodes," Journal of the Electrochemical Society, vol. 153, no. 12, pp. A2255-A2261, 2006.

[42] E. Ramasamy, W. J. Lee, D. Y. Lee, and J. S. Song, "Spray coated multi-wall carbon nanotube counter electrode for tri-iodide $\left(\mathrm{I}_{3}{ }^{-}\right)$reduction in dye-sensitized solar cells," Electrochemistry Communications, vol. 10, no. 7, pp. 1087-1089, 2008.

[43] T. Denaro, V. Baglio, M. Girolamo, et al., "Investigation of low cost carbonaceous materials for application as counter electrode in dye-sensitized solar cells," Journal of Applied Electrochemistry, vol. 39, no. 11, pp. 2173-2179, 2009.

[44] C.-S. Chou, R.-Y. Yang, M.-H. Weng, and C.-I. Huang, "The applicability of SWCNT on the counter electrode for the dyesensitized solar cell," Advanced Powder Technology, vol. 20, no. 4, pp. 310-317, 2009.

[45] P. J. Cameron and L. M. Peter, "Characterization of titanium dioxide blocking layers in dye-sensitized nanocrystalline solar cells," Journal of Physical Chemistry B, vol. 107, no. 51, pp. 14394-14400, 2003.

[46] L. G. Wade, Organic Chemistry, Prentice Hall, Englewood Cliffs, NJ, USA, 1991.

[47] S. Cazzanti, S. Caramori, R. Argazzi, C. M. Elliott, and C. A. Bignozzi, "Efficient non-corrosive electron-transfer mediator mixtures for dye-sensitized solar cells," Journal of the American Chemical Society, vol. 128, no. 31, pp. 9996-9997, 2006.

[48] K. Murakoshi, R. Kogure, Y. Wada, and S. Yanagida, "Fabrication of solid-state dye-sensitized $\mathrm{TiO}_{2}$ solar cells combined with polypyrrole," Solar Energy Materials and Solar Cells, vol. 55, no. 1-2, pp. 113-125, 1998.

[49] S. Caramori, S. Cazzanti, L. Marchini, et al., "Dye-sensitized solar cells based on PEDOP as a hole conductive medium," Inorganica Chimica Acta, vol. 361, no. 3, pp. 627-634, 2008.

[50] D. Martineau, M. Beley, P. C. Gros, S. Cazzanti, S. Caramori, and C. A. Bignozzi, "Tuning of ruthenium complex properties using pyrrole- and pyrrolidine-containing polypyridine ligands," Inorganic Chemistry, vol. 46, no. 6, pp. 2272-2277, 2007.

[51] E. Palomares, J. N. Clifford, S. A. Haque, T. Lutz, and J. R. Durrant, "Slow charge recombination in dye-sensitised solar cells (DSSC) using $\mathrm{Al}_{2} \mathrm{O}_{3}$ coated nanoporous $\mathrm{TiO}_{2}$ films," Chemical Communications, no. 14, pp. 1464-1465, 2002.

[52] Y. Kim, Y. E. Sung, J. B. Xia, M. Lira-Cantu, N. Masaki, and S. Yanagida, "Solid-state dye-sensitized $\mathrm{TiO}_{2}$ solar cells using poly(3,4-ethylenedioxythiophene) as substitutes of iodine/iodide electrolytes and noble metal catalysts on FTO counter electrodes," Journal of Photochemistry and Photobiology A, vol. 193, no. 2-3, pp. 77-80, 2008.

[53] C. M. Elliott, S. Caramori, and C. A. Bignozzi, "Indium tin oxide electrodes modified with tris $\left(2,2^{\prime}\right.$-bipyridine$4,4^{\prime}$-dicarboxylic acid) iron(II) and the catalytic oxidation of tris(4, 4' -di-tert-buty1-2, 2' -bipyridine) cobalt(II)," Langmuir, vol. 21, no. 7, pp. 3022-3027, 2005.

[54] M. J. Scott, J. J. Nelson, S. Caramori, C. A. Bignozzi, and C. M. Elliott, "cis-dichloro-bis $(4,4$ '-dicarboxy-2,2bipyridine)osmium(II)-modified optically transparent electrodes: application as cathodes in stacked dye-sensitized solar cells," Inorganic Chemistry, vol. 46, no. 24, pp. 1007110078, 2007. 


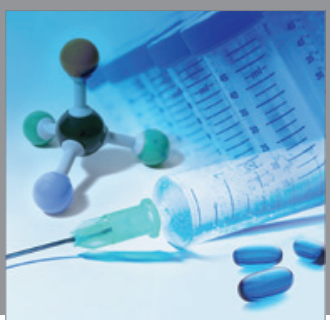

International Journal of

Medicinal Chemistry

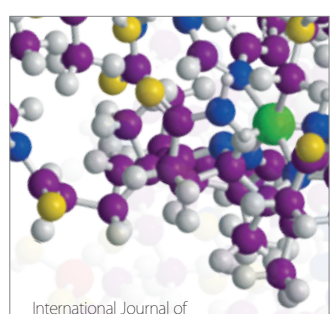

Carbohydrate Chemistry

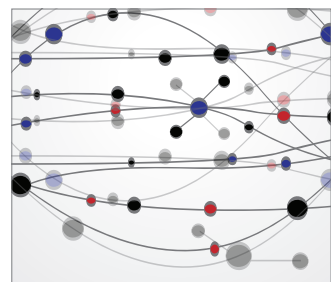

The Scientific World Journal
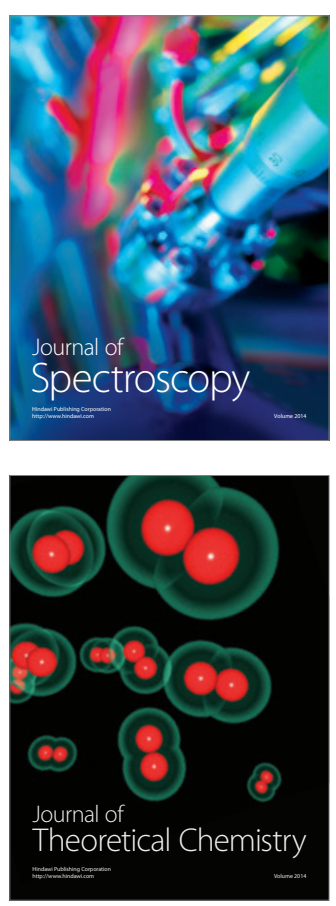
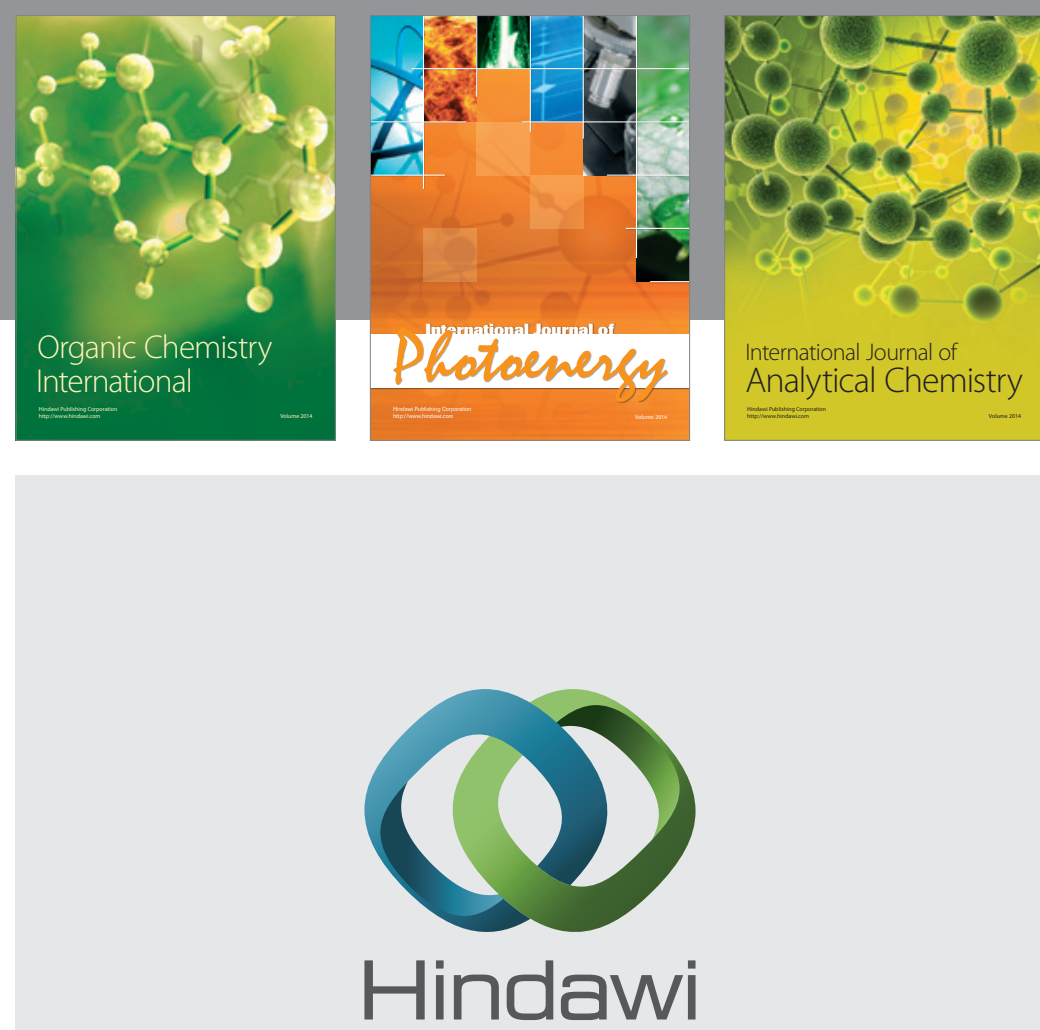

Submit your manuscripts at

http://www.hindawi.com
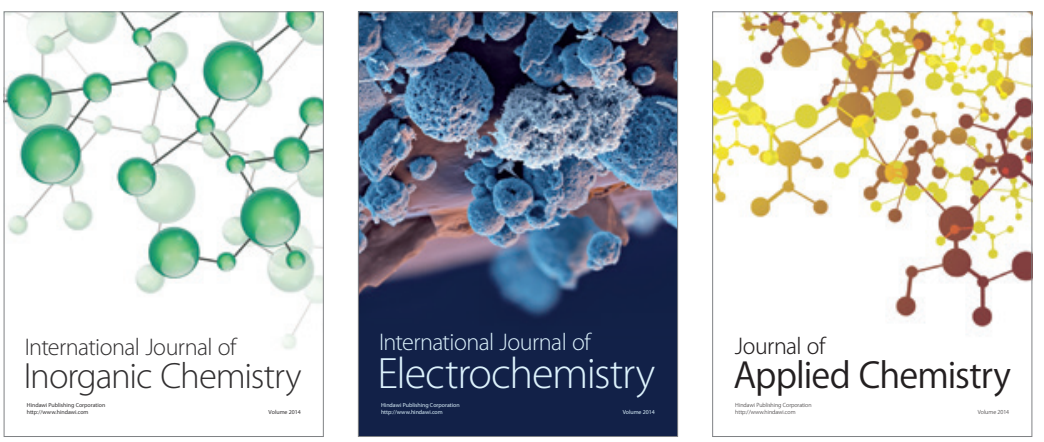

Journal of

Applied Chemistry
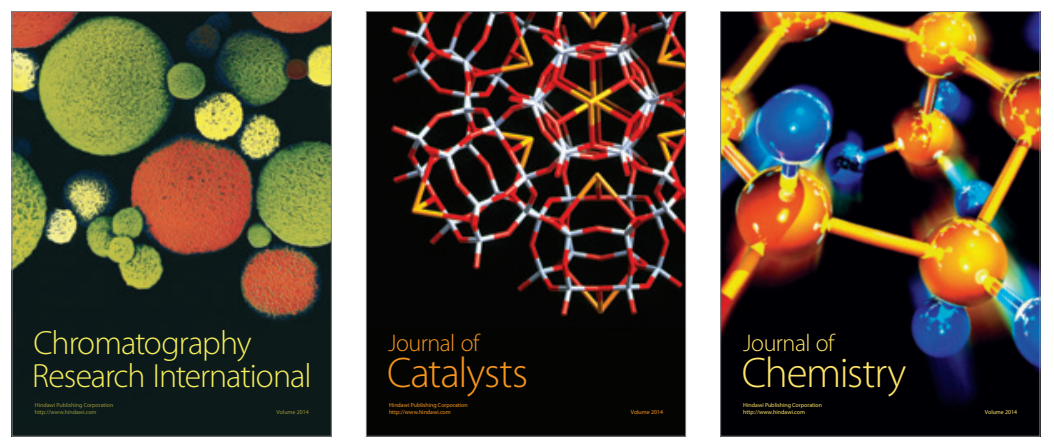
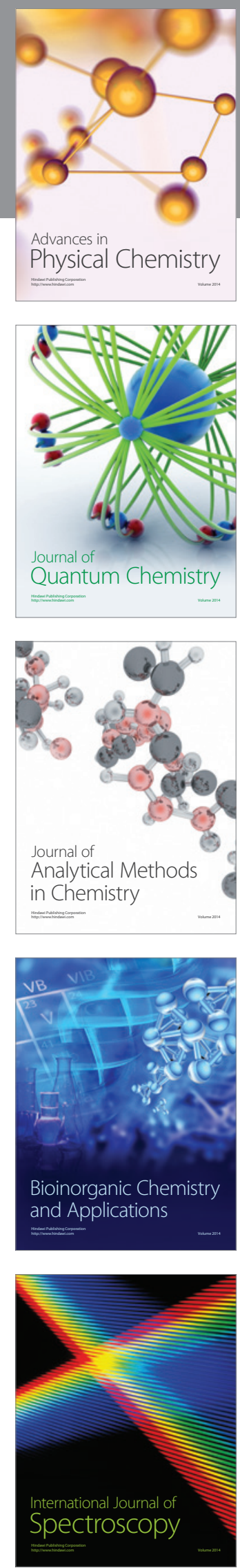